LAWRENCE LIVERMORE NATIONAL LABORATORY

\title{
Aging and Phase Stability of Alloy 22 Welds
}

FY05 SUMMARY REPORT

Sharon G. Torres ${ }^{1}$, Bassem El-Dasher, Michael McGregor, Robert Etien, Tammy S. Edgecumbe, and Greg Gdowski

Yucca Mountain Project

Lawrence Livermore National Laboratory

Nancy Yang, Thomas Headley, Jeff Chames, Ja Lee Yio, and Andy Gardea

Department of Analytical Material Science (8773) Sandia National Laboratories, CA

\section{January 19, 2006}




\section{Disclaimer}

This document was prepared as an account of work sponsored by an agency of the United States Government. Neither the United States Government nor the University of California nor any of their employees, makes any warranty, express or implied, or assumes any legal liability or responsibility for the accuracy, completeness, or usefulness of any information, apparatus, product, or process disclosed, or represents that its use would not infringe privately owned rights. Reference herein to any specific commercial product, process, or service by trade name, trademark, manufacturer, or otherwise, does not necessarily constitute or imply its endorsement, recommendation, or favoring by the United States Government or the University of California. The views and opinions of authors expressed herein do not necessarily state or reflect those of the United States Government or the University of California, and shall not be used for advertising or product endorsement purposes.

\section{Auspices}

This work was performed under the auspices of the U.S. Department of Energy by University of California, Lawrence Livermore National Laboratory under Contract W-7405-Eng-48. 


\section{TABLE OF CONTENTS}

Executive Summary

1. Introduction 1

1.1. Background 1

1.2. Experimental Techniques 2

1.2.1. Image Analysis

1.2.2. Electron Backscatter Diffraction

1.2.3. Wavelength Dispersive Spectroscopy

1.2.4. Electron Microprobe Analysis

1.3. DTN Listing 4

2. Thermal Aging Facilities 6

3. Solution Annealing of Alloy 22 Thick (1.25") Welds 8

$\begin{array}{lll}\text { 3.1. } & \text { Methods } & 8\end{array}$

3.1.1. TCP Phase Quantification and Mapping

3.1.2. Crystallographic Orientation Mapping

3.1.3. Cyclic Polarization Tests

3.2. Results and Discussion

3.2.1. Phase Stability and Recrystallization

3.2.2. Corrosion Behavior

3.3. Summary 23

4. Mock-up Waste Package Studies 24

4.1. Methods 24

4.1.1. TCP Phase Quantification

4.1.2. Phase Identification

4.1.3. TCP Phase Chemical Composition 
4.2. Results and Discussion 25

4.2.1. TCP Phase Stability

4.2.2. TCP Phase Identification

4.2.3. TCP Phase Chemical Composition

4.3. Summary

5. Effect of Stress Mitigation Processes on Secondary Phase Precipitation during Thermal Aging

5.1. Methods

5.1.1. TCP Phase Quantification

5.1.2. TCP Phase Identification

5.1.3. LRO Characterization

5.2. Results and Discussion

5.2.1. Phase Stability

5.2.2. Phase Identities

5.2.3. LRO Characterization

5.3. Summary 36

6. Evaluation of Weld Stability 37

$\begin{array}{lll}\text { 6.1. } & \text { Methods } & 37\end{array}$

6.2. Results and Discussion 37

6.3. Summary 39

7. Haynes 11.4 year (100,000 hour) Aged Welds 40

$\begin{array}{lll}\text { 7.1. } & \text { Methods } & 40\end{array}$

7.2. Results and Discussion 40

7.3. Summary 43

8. References 44 


\section{Executive Summary}

Evaluation of the fabrication processes involved in the manufacture of waste containers is important as these processes can have an effect on the metallurgical structure of an alloy. Since material properties such as strength, toughness, aging kinetics and corrosion resistance are all dependent on the microstructure, it is important that prototypes be built and evaluated for processing effects on the performance of the material. Of particular importance are welds, which have an as-cast microstructure with chemical segregation and precipitation of complex phases resulting from the welding process. The work presented in this report focuses on the effects of processes such as solution annealing, stress mitigation, and welding on the kinetics of precipitation and corrosion properties.

For a waste package lifetime of thousands of years, it is impossible to test directly in the laboratory the behavior of Alloy 22 under expected repository conditions. The changes that may occur in these materials must be accelerated. For phase-stability studies this is achieved by accelerating the phase transformations by increasing test temperatures above those anticipated in the proposed repository. For these reasons, Alloy 22 characterization specimens are currently being aged at Lawrence Livermore National Laboratory (LLNL) Aging Facilities for times from 1 hour to 20 years at temperatures ranging from $200-750^{\circ} \mathrm{C}$. These data as well as the data from specimens aged at $260^{\circ} \mathrm{C}, 343^{\circ} \mathrm{C}$, and $427^{\circ} \mathrm{C}$ for 100,000 hours at Haynes International will be used for performance confirmation.

The six activities described in this report are listed below, along with their respective salient results and conclusions:

\section{Maintenance of the Low and High Temperature Aging Facilities}

The Aging Facilities allow LLNL to provide information and insight on how prototypes could best be manufactured with respect to heat treatment parameters and to perform the evaluations of processing effects on material performance. Evaluation of fabrication processes is important because fabrication can have an effect on the metallurgical structure of an alloy and on the condition of the surface.

Experimental data acquired from specimens aged in the Aging Facilities can provide enhanced confidence in model predictions. The objective of the Aging/Phase Stability (APS) model is to provide a quantitative model which can be used to predict the amount of any phases forming as a function of both time and temperature. The APS model is currently used to provide predictive insight into the long-term metallurgical stability of Alloy 22 base metal under repository conditions. Experimental data acquired from welds will be available when the APS model is expanded to include welds.

\section{Evaluation of Solution Annealing Parameters for Alloy 22 Thick (1.25") Welds}

Tetrahedrally close-packed (TCP) phases were present in specimens that were solution annealed for 20 minutes at $1075^{\circ} \mathrm{C}$ and $1121^{\circ} \mathrm{C}$, and in the as-welded specimen. The volume fractions measured were $<1 \%$ and the TCP phases were not homogeneously dispersed, therefore the relative error associated with the values is high. NOTE: The values measured should only be used as an indication of the presence of TCP phases.

Based on the results, it was observed that solution annealing at higher temperatures $\left(1200^{\circ} \mathrm{C}\right.$ and $\left.1300^{\circ} \mathrm{C}\right)$ or longer durations at lower temperatures $\left(1075^{\circ} \mathrm{C}\right.$ and $\left.1121^{\circ} \mathrm{C}\right)$ are required to 
dissolve TCP phases. Considering the coarsening observed in the $1300^{\circ} \mathrm{C}$ specimen, and the relatively homogeneous nature of the grain structure in the $1200^{\circ} \mathrm{C}$ specimen, the choice of solution annealing at $1200^{\circ} \mathrm{C}$ for 20 minutes appears to be the most appropriate process to perform from a microstructural point of view.

Overall the effects of solution annealing on Alloy 22 corrosion behavior in $6 \mathrm{~m} \mathrm{NaCl}+0.9 \mathrm{~m}$ $\mathrm{KNO}_{3}$ at $100^{\circ} \mathrm{C}$ are similar to those found for $1 \mathrm{M} \mathrm{NaCl}$ at $90^{\circ} \mathrm{C}$. Optical microscopy examination indicates less localized corrosion degradation with increasing annealing temperatures in both the $1 \mathrm{M} \mathrm{NaCl}$ and $6 \mathrm{~m} \mathrm{NaCl}+0.9 \mathrm{~m} \mathrm{KNO}_{3}$. However, residual surface oxide from the annealing process may have obscured the quantification of the localized corrosion susceptibility from the CPP curves.

\section{Effects of Stress Mitigation Processes on Secondary Phase Precipitation during Thermal Aging}

Alloy 22 weld specimens subject to the stress mitigation techniques of low plasticity burnishing and laser shock peening were studied by Lawrence Livermore National Laboratory (LLNL) for TCP phase stability by aging them at $700^{\circ} \mathrm{C}$ for 50 and 500 hours. Aging for 50 hours provided little change in the observable TCP phase content, with total volume fraction near $0.1 \%$. Aging for 500 hours increased the amount of TCP phases, which primarily precipitated in between the secondary dendrites of the weld fusion zone.

Alloy 22 weld specimens subjected to the same stress mitigation techniques were characterized by Sandia National Laboratory (SNL) for the presence of (LRO) by aging them at $550^{\circ} \mathrm{C}$ for 1000 hours. Characterization of the non-aged as-welded specimen showed no signs of LRO. All the aged samples contained a fine microstructure which consisted of a mix of dislocations and the ordered phase. Due to the difficult nature of quantification of objects in TEM micrographs, values for the volume fraction of LRO in the aged specimens are still being calculated. However, based on the TEM micrographs obtained from each of the aged specimens, it is apparent that they all contain a high fraction of the ordered phase. Additionally, the burnished sample contained a high density of twins.

\section{Evaluation of Mockup Waste Package "Hockey Pucks"}

Specimens encompassing the full width of longitudinal seam welds were cut from two hockey pucks. The pucks were extracted from a $1 / 4$ scale mockup, one from the "exposed" longitudinal seam weld and the other from the "unexposed" longitudinal seam weld located under the trunnion collar intended for lifting the waste package. It was observed that solution annealing of the mockup waste package appears to decrease the total amount of TCP phases in the fusion zone of the weld. However, the weld region beneath the trunnion showed an increase in the amount of secondary phases near the surface of the weld.

The TCP phase that formed at the surface of the hockey puck trunnion weld was identified as $\sigma$. Chemical segregation occurs during the formation of sigma and the matrix is depleted of nickel in the areas adjacent to the sigma phase. Since this weld was located under the trunnion, the weld experienced a slower rate of cooling allowing time for the formation of the sigma phase, which was not observed in the other longitudinal seam weld from the same mockup.

\section{Evaluation of Weld Stability in Prototypical Thick Welds}

Analyses of six of the seventeen Alloy 22 thick ( 1.25 ") weld specimens that were aged from 200 to $750^{\circ} \mathrm{C}$ (see TWP-WIS-MD-000011) were conducted. The specimens analyzed to date are those aged at $650^{\circ} \mathrm{C}$ for 20 and 100 hours and the remaining four at $700^{\circ} \mathrm{C}$ and $750^{\circ} \mathrm{C}$ for 10 and 100 hours, respectively. The TCP phase kinetics are fastest at $750^{\circ} \mathrm{C}$ resulting in an increase in 
volume fraction of TCP phases to approximately $6 \%$. Studies on the TCP phase formation in an as-welded specimen and specimens aged for longer durations at these and other temperatures are on-going.

\section{Characterization of Gas Tungsten Arc Welded (GTAW) 100,000 Hour ( 11.4 years) Thermally Aged Haynes, International Welds}

GTAW 0.5" welded plates were aged at Haynes, International for $\sim 11.4$ years. The characterization of three specimens aged at 260,343 , and $427^{\circ} \mathrm{C}$ were performed by SNL (Livermore, CA). Analyses by TEM of the specimen aged at $427^{\circ} \mathrm{C}$ showed the presence of long range ordering with varying particle sizes throughout the specimen. TCP phases were present in the fusion zone of the welds as a result of the welding process. Comparison of a non-aged, aswelded specimen to specimens aged at $260^{\circ} \mathrm{C}$ and $343^{\circ} \mathrm{C}$ for 100,000 hours showed no differences in the TCP phase morphology and size. P and sigma were the only TCP phases observed in the weld aged at $427^{\circ} \mathrm{C}$ for 100,000 hours and LRO was also present.

TCP phases within the weld appeared in the Scanning Electron Microscope (SEM) to be the same in all three specimens, however, the presence of LRO is currently being evaluated for the specimens aged at 260 and $343^{\circ} \mathrm{C}$ for 100,000 hours. 


\section{Introduction}

\subsection{Background}

The current design for nuclear waste containers in the repository at Yucca Mountain consists of an inner container of 316 NG stainless steel for structural integrity and an outer container of a $\mathrm{Ni}-\mathrm{Cr}$-Mo alloy, referred to in the Yucca Mountain Project as Alloy 22 (UNS \#N06022) on the outside for corrosion resistance. In order to fabricate the containers, welds will be required; the weld process currently being considered is Gas Tungsten Arc Welding (GTAW). Each container would be fabricated by bending or rolling plates into cylinders, using a longitudinal weld to close the seam and then welding two or more of these cylinders together with a circumferential weld to obtain appropriate lengths. After welding on the bottom lid, the entire container would be solution annealed to eliminate any residual stresses in the material resulting from fabrication processes. The containers would be filled, and final closure welds would weld Alloy 22 lids onto the container. These closure welds cannot be heat treated as the other welds because the waste cannot be taken to the temperatures required to solution anneal the Alloy 22. Because stress corrosion cracking is now considered one of the most likely failure mechanisms for the waste package, it is currently proposed to mitigate the residual stresses in the Alloy 22 closure weld by burnishing or laser shock peening the weld to put the residual stresses into compression.

The containers are required to maintain integrity without substantial leakage for a long duration. This long lifetime combined with a somewhat elevated temperature from the heat generated by radioactive decay of the waste (approximately $180^{\circ} \mathrm{C}$ ), makes characterization of the materials involved essential. For most engineering applications these temperatures are low; however the times involved are very long. Consequently, one area of concern is phase stability of the waste container materials since the precipitation of deleterious phases over such long times can affect the corrosion resistance and/or the mechanical properties of the Alloy 22 welds as well as the base metal.

Previous work shows that above approximately $600^{\circ} \mathrm{C}$ up to at least $760^{\circ} \mathrm{C}$, Tetrahedrally Close-Packed (TCP) phases [1] (primarily the Mo-rich $\mu$ and $P$ phases) form. Because Mo provides the Ni-Cr-Mo alloys with their resistance to localized corrosion, segregation of the Mo to the TCP phases can cause a depletion of Mo in the matrix and lead to localized corrosion. Below approximately $600^{\circ} \mathrm{C}, \mathrm{Ni}_{2}(\mathrm{Cr}, \mathrm{Mo})$, which has an ordered $\mathrm{Pt}_{2} \mathrm{Mo}$-type structure, forms [2,4,5-7]. This long-range ordering has been linked to an increased susceptibility to stress corrosion cracking and hydrogen embrittlement [2]. Cieslak et al. [8] and Ogborn et al. [9] investigated the microstructures of Alloy 22 welds and found segregation of Mo but also to some extent $\mathrm{W}$ in the interdendritic regions of the weld. This enrichment of Mo and $W$ causes TCP phase precipitation to occur during the welding of Alloy 22, with $\mu, \mathrm{P}$, and $\sigma$ phases forming in the fusion zone. This segregated structure tends to increase the corrosion rate somewhat over the rate of base metal $[10,11]$ and reduces ductility [12]. In order to predict long-term behavior of the welds, it is important to know whether these precipitates present in the as-welded condition are thermodynamically stable at the low repository temperatures and, if so, how fast they grow and what effect they have on the properties of the weld. 


\subsection{Experimental Techniques}

This section details the two methods applied in the metallurgical characterization of specimens studied in this work. The two methods are Image Analysis, used primarily for determining secondary phase volume fractions, and Electron Backscatter Diffraction (EBSD), used to identify secondary (TCP) phases or map the evolution of recrystallization/grain growth. Both characterization techniques require a polished specimen surface. All specimens evaluated were metallurgically prepared by successively grinding the surface to 1200 grit silicon carbide paper, followed by successive polishing to $0.02 \mu \mathrm{m}$ colloidal silica.

\subsubsection{Image Analysis}

This technique is composed of two distinct steps. The first involves imaging the specimen to acquire enough micrographs that are statistically representative of the secondary phases present (if any) in a specimen. Since the primary focus is the determination of the amount of precipitation of TCP phases, differences in the chemical composition between the matrix and the secondary phases can be imaged by using a backscatter electron detector in the Scanning Electron Microscope (SEM). Since the amount of electrons backscattered in a volume of material is directly proportional to the atomic $Z$ number of the material, the TCP phases show up with a higher intensity (white) than the matrix (black).
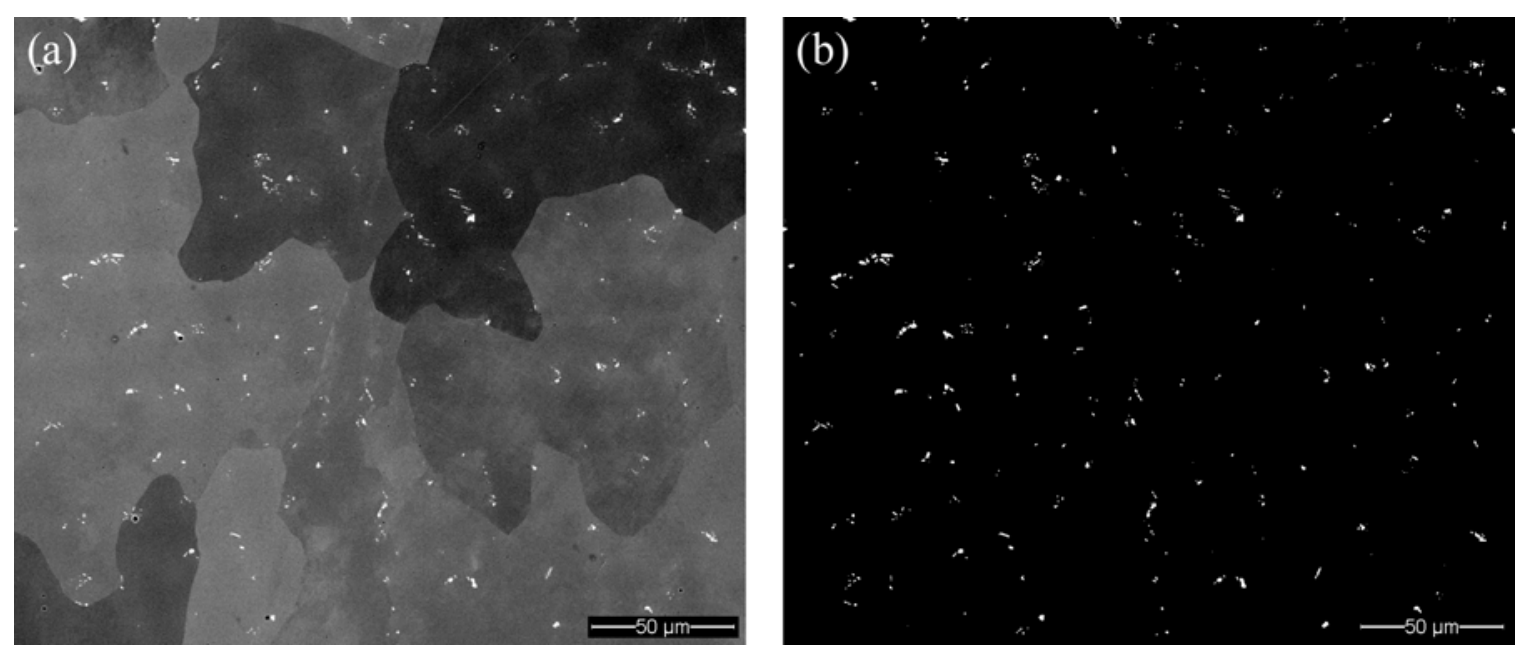

Figure 1.2.1.1. (a) Backscattered electron SEM micrograph captured in the fusion zone of an as-welded specimen. Due to compositional differences the TCP phases appear white. (b) Thresholded image of Figure 1.2.1.1 (a). (Source: DTN LL050303712251.029)

By applying a grayscale threshold to the captured micrographs all pixels in the image corresponding to the matrix are effectively eliminated. From the resulting image, the TCP phase content of the imaged area can be determined as the ratio of remaining pixels to the total number of pixels in the area. Image analysis software output consists of an area fraction of the remaining pixels. Figure 1.2.1.1 is an example of the thresholding procedure for a micrograph obtained from the fusion zone of a weld.

While this technique is highly effective in measuring the TCP phase content, it can potentially be utilized to estimate the volume fraction of long range ordering (LRO). LRO precipitates show up as bright objects in a Transmission Electron Microscope (TEM). However, since LRO micrographs are acquired in a TEM, the micrographs represent the projection of a three dimensional volume (versus a section plane), the thickness of the observed section needs to be taken into account. Since within a given region the volume fraction varies appreciably between the six crystallographically related variants and within a given variant the volume fraction varies 
from region to region on a scale of $\sim 0.2-0.4 \mu \mathrm{m}$, principles of stereology need to be applied to account for overlapping ordered precipitates. At the time of writing the development of this method is still incomplete, and so no results will be presented regarding quantification of LRO.

\subsubsection{Electron Backscatter Diffraction}

Electron Backscatter Diffraction (EBSD) is a technique in which a focused beam of electrons coincides with the crystalline surface of the specimen at a shallow angle (typically $20^{\circ}$ ), causing electrons to backscatter. The shallow angle restricts the backscattered electrons that escape to those that can pass without interference to the atoms lying in the crystalline planes of the material. Due to this limitation, the electrons that escape do so in a conical pattern.

A phosphor screen in the path of the escaping electrons allows the observation of part of this cone, in the form of a band. Since multiple crystal planes cause diffraction, multiple bands can be seen and form a diffraction pattern. This pattern is then imaged using a CCD camera and software can be used to obtain information from the pattern. Since the width and geometric relationship of these bands is material and phase dependent, the observed diffraction pattern can be used to determine the local crystal orientation as well as identify the source phase of the diffraction. Specimens were tilted to $70^{\circ}$ in the SEM chamber and an accelerating voltage of $30 \mathrm{kV}$ with a beam current of $98 \mu \mathrm{A}$ was used in spot mode. Figure 1.2.2.1 shows a schematic of the diffraction as well as an EBSD pattern for nickel.
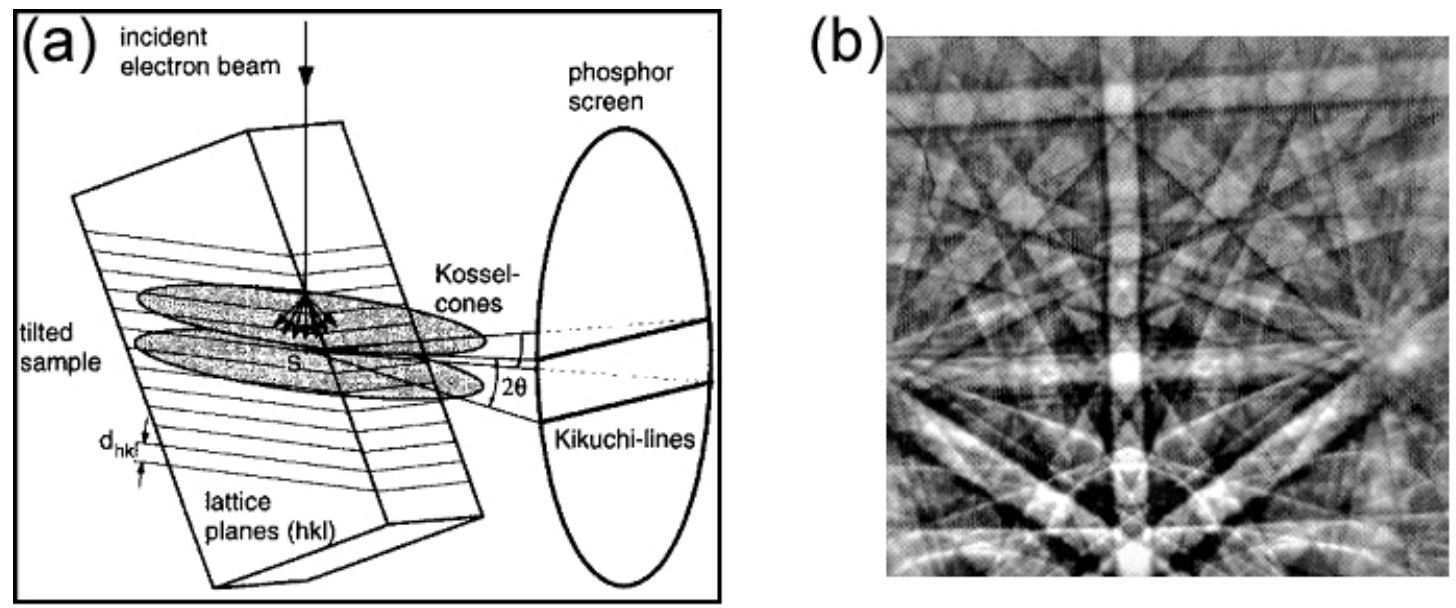

Figure 1.2.2.1. (a) Schematic of the source of diffraction bands observed in (b), the diffraction pattern from a nickel crystal.

\subsubsection{Wavelength Dispersive Spectroscopy}

Wavelength dispersive spectroscopy (WDS) is a technique used for the determination of the chemical composition of materials. A focused electron beam is used, which during the interaction with the material being analyzed produces characteristic X-rays that are analyzed by a specially designed detector. These $X$-rays are effectively the signature of the elements within the material, since each element produces X-rays with a characteristic wavelength. All X-rays of all wavelengths (within the detector range) are counted, and the relative intensities (counts) of the elements in question are used to determine the chemical composition of the material. The advantage of WDS versus the more commonly used Energy Dispersive Spectroscopy (EDS) is the discriminatory ability of WDS in detecting the wavelength of emitted X-rays. 


\subsubsection{Electron Microprobe Analysis}

Electron Microprobe Analysis (EMPA) is also a technique used for determining the chemical composition of materials used by the analysis of X-rays produced from electron beam interactions with the material. In EMPA, the high-energy of the electron beam used allows the generation of $X$-rays characteristic of the elements within sample volumes as small as $3 \mu \mathrm{m}$ across. These resulting X-rays are diffracted by analyzing crystals and are counted using gas-flow and sealed proportional detectors. Chemical composition is determined by comparing the intensity of X-rays from standards of a known composition with those from unknown materials and correcting for the effects of absorption and fluorescence in the sample. The major difference between EMPA and other methods is the intensity of the electron beam used, which allows for a more accurate and sensitive analysis.

\subsection{Data Tracking Number (DTN) Listing}

Table 1.3.1. List of DTN's and associated notebooks for analyses contained in this report.

\begin{tabular}{|c|c|c|}
\hline $\begin{array}{c}\text { DTN and } \\
\text { Notebook Numbers }\end{array}$ & Title of Data & $\begin{array}{l}\text { Report } \\
\text { Section }\end{array}$ \\
\hline $\begin{array}{l}\text { LL050303512251.027 } \\
\text { SN-LLNL-SCI-441-V2 }\end{array}$ & $\begin{array}{l}\text { Large Scale Electron Backscatter Diffraction Data of } 1.5^{\prime \prime} \text { Thick } \\
\text { Double-U Alloy } 22 \text { Weld Specimens As-welded and Solution } \\
\text { Annealed at } 1075^{\circ} \mathrm{C}, 1121^{\circ} \mathrm{C}, 1200^{\circ} \mathrm{C} \text { and } 1300^{\circ} \mathrm{C} \text { for Various } \\
\text { Times and Conditions }\end{array}$ & 3 \\
\hline $\begin{array}{l}\text { LL050303612251.028 } \\
\text { SN-LLNL-SCI-441-V2 }\end{array}$ & $\begin{array}{l}\text { Large Scale Electron Backscatter Diffraction Maps (EBSDM) of } \\
\text { 1.5" Thick Double-U Alloy } 22 \text { Weld Specimens As-welded and } \\
\text { Solution Annealed at } 1075^{\circ} \mathrm{C}, 1121^{\circ} \mathrm{C}, 1200^{\circ} \mathrm{C} \text { and } 1300^{\circ} \mathrm{C} \text { for } \\
\text { Various Times and Conditions }\end{array}$ & 3 \\
\hline $\begin{array}{l}\text { LL050303712251.029 } \\
\text { SN-LLNL-SCI-441-V2 }\end{array}$ & $\begin{array}{l}\text { Scanning Electron Microscope (SEM) Images of } 1.5^{\prime \prime} \text { Thick } \\
\text { Double-U Alloy } 22 \text { Weld Specimens As-welded and Solution } \\
\text { Annealed at } 1075^{\circ} \mathrm{C}, 1121^{\circ} \mathrm{C}, 1200^{\circ} \mathrm{C} \text { and } 1300^{\circ} \mathrm{C} \text { for Various } \\
\text { Times and Conditions }\end{array}$ & 3 \\
\hline $\begin{array}{l}\text { LL050303812251.030 } \\
\text { SN-LLNL-SCI-441-V2 }\end{array}$ & $\begin{array}{l}\text { Tetrahedrally Close Packed (TCP) Phase Volume Fraction } \\
\text { Data of } 1.5^{\prime \prime} \text { Thick Double-U Alloy } 22 \text { Weld Specimens As- } \\
\text { welded and Solution Annealed at } 1075^{\circ} \mathrm{C}, 1121^{\circ} \mathrm{C}, 1200^{\circ} \mathrm{C} \text { and } \\
1300^{\circ} \mathrm{C} \text { for Various Times and Conditions }\end{array}$ & 3 \\
\hline $\begin{array}{l}\text { LL050303912251.031 } \\
\text { SN-LLNL-SCI-441-V2 }\end{array}$ & $\begin{array}{l}\text { Scanning Electron Microscope (SEM) Images of 1.5" Thick } \\
\text { Double-U Alloy } 22 \text { Welds Used for Construction of Large-scale } \\
\text { Weld Maps of Specimens in the As-welded and Solution } \\
\left.\text { Annealed ( } 1121^{\circ} \mathrm{C} / 20 \mathrm{~min}\right) \text { Conditions }\end{array}$ & 3 \\
\hline $\begin{array}{l}\text { LL050304012251.032 } \\
\text { SN-LLNL-SCI-441-V2 }\end{array}$ & $\begin{array}{l}\text { Large-scale Collages of Analyzed Scanning Electron } \\
\text { Microscope (SEM) Images of 1.5" Thick Double-U Alloy } 22 \\
\text { Welds for Specimens in the As-welded and Solution Annealed } \\
\left(1121^{\circ} \mathrm{C} / 20 \mathrm{~min}\right) \text { Conditions }\end{array}$ & 3 \\
\hline $\begin{array}{l}\text { LL050803712251.036 } \\
\text { SN-LLNL-SCI-463-V3 }\end{array}$ & $\begin{array}{l}\text { Effect of Solution Annealing Temperature on the Anodic } \\
\text { Behavior of Alloy } 22 \text { Thick Welds }\end{array}$ & 3 \\
\hline \begin{tabular}{|l} 
LL050803812251.037 \\
SN-LLNL-SCl-463-V3
\end{tabular} & $\begin{array}{l}\text { Repassivation Potentials of Alloy } 22 \text { Thick Welds Solution } \\
\text { Annealed at Different Temperatures }\end{array}$ & 3 \\
\hline $\begin{array}{l}\text { LL050304112251.134 } \\
\text { SN-LLNL-SCI-426-V1 }\end{array}$ & $\begin{array}{l}\text { Electron Backscatter Diffraction Data Obtained From the Top } \\
\text { of the Trunnion Weld of a Specimen from a Solution Annealed, } \\
\text { Quarter-scale, Alloy 22, Mockup Waste Package }\end{array}$ & 4 \\
\hline $\begin{array}{l}\text { LL050304212251.135 } \\
\text { SN-LLNL-SCI-426-V1 }\end{array}$ & $\begin{array}{l}\text { Electron Backscatter Diffraction Maps (EBSDM) obtained at } \\
\text { the Top of the Trunnion Weld of a Specimen from a Solution } \\
\text { Annealed, Quarter-scale, Alloy 22, Mockup Waste Package }\end{array}$ & 4 \\
\hline
\end{tabular}




\begin{tabular}{|c|c|c|}
\hline $\begin{array}{l}\text { LL050304312251.136 } \\
\text { SN-LLNL-SCI-426-V1 }\end{array}$ & $\begin{array}{l}\text { Scanning Electron Microscope (SEM) Images of the Cross- } \\
\text { Section of the Seam and Trunnion Welds of Specimens } \\
\text { Prepared from a Solution Annealed, Quarter-scale, Alloy 22, } \\
\text { Mockup Waste Package }\end{array}$ & 4 \\
\hline $\begin{array}{l}\text { LL050304412251.137 } \\
\text { SN-LLNL-SCI-426-V1 }\end{array}$ & $\begin{array}{l}\text { Tetrahedrally Close Packed (TCP) Phase Volume Fraction } \\
\text { Data from the Seam and Trunnion Welds of Specimens } \\
\text { Prepared from a Solution Annealed, Quarter-scale, Alloy 22, } \\
\text { Mockup Waste Package }\end{array}$ & 4 \\
\hline $\begin{array}{l}\text { LL050901612251.041 } \\
\text { SN-LLNL-SCl-426-V2 }\end{array}$ & $\begin{array}{l}\text { Wavelength Dispersive Spectroscopy (WDS) Results of } \\
\text { Hockey Puck Trunnion Longitudinal Seam Weld Specimen }\end{array}$ & 4 \\
\hline $\begin{array}{l}\text { LL050303112251.023 } \\
\text { SN-LLNL-SCI-459-V1 }\end{array}$ & $\begin{array}{l}\text { High Magnification Scanning Electron Microscope (SEM) } \\
\text { Images and Electron Backscatter Diffraction patterns (EBSDP) } \\
\text { of Tetrahedrally close-packed (TCP) Phase Particles in As- } \\
\text { welded, Low Plasticity Burnished and Laser Shock Peened } \\
\text { Alloy } 221.25 " \text { Thick Welds Aged for Various Times at } 700^{\circ} \mathrm{C}\end{array}$ & 5 \\
\hline $\begin{array}{l}\text { LL050303212251.024 } \\
\text { SN-LLNL-SCI-459-V1 }\end{array}$ & $\begin{array}{l}\text { Individual Tetrahedrally close-packed (TCP) Phase Type } \\
\text { Volume Fraction Data of As-welded, Low Plasticity Burnished } \\
\text { and Laser Shock Peened Alloy } 221.25^{\prime \prime} \text { Thick Welds Aged for } \\
\text { Various Times at } 700^{\circ} \mathrm{C}\end{array}$ & 5 \\
\hline $\begin{array}{l}\text { LL050303312251.025 } \\
\text { SN-LLNL-SCI-459-V1 }\end{array}$ & $\begin{array}{l}\text { Scanning Electron Microscope (SEM) Images of As-welded, } \\
\text { Low Plasticity Burnished and Laser Shock Peened Alloy } 22 \\
1.25 \text { "Thick Welds Aged for Various Times at } 700^{\circ} \mathrm{C}\end{array}$ & 5 \\
\hline $\begin{array}{l}\text { LL050303412251.026 } \\
\text { SN-LLNL-SCI-459-V1 }\end{array}$ & $\begin{array}{l}\text { Tetrahedrally close-packed (TCP) Phase Volume Fraction Data } \\
\text { of As-welded, Low Plasticity Burnished and Laser Shock } \\
\text { Peened Alloy } 221.25 " \text { Thick Welds Aged for Various Times at } \\
700^{\circ} \mathrm{C}\end{array}$ & 5 \\
\hline $\begin{array}{l}\text { LL050901312251.038 } \\
\text { SN-LLNL-SCl-459-V1 }\end{array}$ & $\begin{array}{l}\text { Transmission Electron Microscopy (TEM) Images of Aged } \\
\text { Stress Mitigated Alloy } 22 \text { Welds }\end{array}$ & 5 \\
\hline $\begin{array}{l}\text { LL0500304512251.138 } \\
\text { SN-LLNL-SCl-441-V3 }\end{array}$ & $\begin{array}{l}\text { Scanning Electron Microscope (SEM) Images of Alloy } 22 \text { weld } \\
\text { specimens aged at } 650^{\circ} \mathrm{C} \text { for } 20 \text { and } 100 \text { hours }\end{array}$ & 6 \\
\hline $\begin{array}{l}\text { LL050304612251.139 } \\
\text { SN-LLNL-SCI-441-V3 }\end{array}$ & $\begin{array}{l}\text { Scanning Electron Microscope (SEM) Images of Alloy } 22 \text { weld } \\
\text { specimens aged at } 700^{\circ} \mathrm{C} \text { for } 10 \text { and } 100 \text { hours }\end{array}$ & 6 \\
\hline $\begin{array}{l}\text { LL050304712251.140 } \\
\text { SN-LLNL-SCI-441-V3 }\end{array}$ & $\begin{array}{l}\text { Scanning Electron Microscope (SEM) Images of Alloy } 22 \text { weld } \\
\text { specimens aged at } 750^{\circ} \mathrm{C} \text { for } 10 \text { and } 100 \text { hours }\end{array}$ & 6 \\
\hline $\begin{array}{l}\text { LL050304912251.142 } \\
\text { SN-LLNL-SCI-441-V3 }\end{array}$ & $\begin{array}{l}\text { Tetrahedrally close-packed (TCP) Phase Volume Fraction Data } \\
\text { of Alloy } 22 \text { Thick Welds aged at } 650^{\circ} \mathrm{C} \text { for } 20 \text { and } 100 \text { hours, at } \\
700^{\circ} \mathrm{C} \text { for } 10 \text { and } 100 \text { hours, and } 750^{\circ} \mathrm{C} \text { for } 10 \text { and } 100 \text { hours }\end{array}$ & 6 \\
\hline $\begin{array}{l}\text { LL030301612251.040 } \\
\text { SN-LLNL-SCI 393-V1 }\end{array}$ & $\begin{array}{l}\text { Transmission Electron Microscopy (TEM), Scanning Electron } \\
\text { Microscopy (SEM), and Optical Microscopy of Aged Alloy } 22 \\
\text { Weld Metal Samples }\end{array}$ & 7 \\
\hline $\begin{array}{l}\text { LL021009912251.003 } \\
\text { SN-LLNL-SCI-441-V2 }\end{array}$ & $\begin{array}{l}\text { Scanning Electron Microscope (SEM) Micrographs of Gas- } \\
\text { Tungsten Arc-Welded (GTAW) Haynes Alloy } 22 \text { Samples (As- } \\
\text { Welded) and Aged at Various Times and Temperatures Used } \\
\text { For Area Fraction Measurements of Topologically close- } \\
\text { packed (TCP) Phases }\end{array}$ & 7 \\
\hline $\begin{array}{l}\text { LL050901412251.039 } \\
\text { SN-LLNL-SCI-442-V1 }\end{array}$ & $\begin{array}{l}\text { Transmission Electron Microscopy (TEM) Images of Haynes } \\
11.4 \text { Year Aged Alloy } 22 \text { Weld at } 427^{\circ} \mathrm{C}\end{array}$ & 7 \\
\hline $\begin{array}{l}\text { LL050901512251.040 } \\
\text { SN-LLNL-SCI-442-V1 }\end{array}$ & $\begin{array}{l}\text { Scanning Electron Microscopy (SEM) Images of Haynes } 11.4 \\
\text { Year Aged Alloy } 22 \text { Welds at } 260^{\circ} \mathrm{C} \text { and } 343^{\circ} \mathrm{C}\end{array}$ & 7 \\
\hline
\end{tabular}




\section{Thermal Aging Facilities}

The Aging Facilities play a key role in assessing the long-term corrosion and metallurgical performance of samples from full-scale waste package prototypes to help formulate a definitive assessment of the effects of manufacturing processes on material performance.

Experimental data acquired from specimens aged in the Aging Facility provide enhanced confidence in model predictions. The Aging/Phase Stability (APS) model provides a quantitative model that is used to predict the amount of any secondary phases forming as a function of both time and temperature. The APS model is used to provide predictive insight into the long-term metallurgical stability of Alloy 22 extrapolated to thousands of years.

Current modeling only predicts transformations in bulk base metal (based on a simplified ternary composition) and not welds. The kinetics of precipitation on grain boundaries and in welds are measured experimentally and compared to the theoretical predictions in bulk base metal. Without these experimental data the kinetics of precipitation in welds cannot be predicted. Given the short-term nature of these data, predictions will remain highly uncertain until theoretical calculations that take into consideration the numerous phases involved, their compositions, and chemical segregation in the weld are performed and experimentally validated.

Figure 2.1 shows the high temperature Aging/Salt Bath Facilities at LLNL, where base metal characterization and tensile blanks have been aging at temperatures between $400-650^{\circ} \mathrm{C}$ since 1998 and Alloy 22 thick (1.25") welds which were added in 2005. The Salt Bath Furnace is capable of heating specimens to high temperatures within seconds, thereby eliminating the lag time of waiting for a furnace to reach its test temperature. Figure 2.2 shows the low temperature Aging Facility where base metal characterization and tensile blanks and Alloy 22 thick (1.25") welds have been aging at $200^{\circ} \mathrm{C}$ and $300^{\circ} \mathrm{C}$ since 2004 .

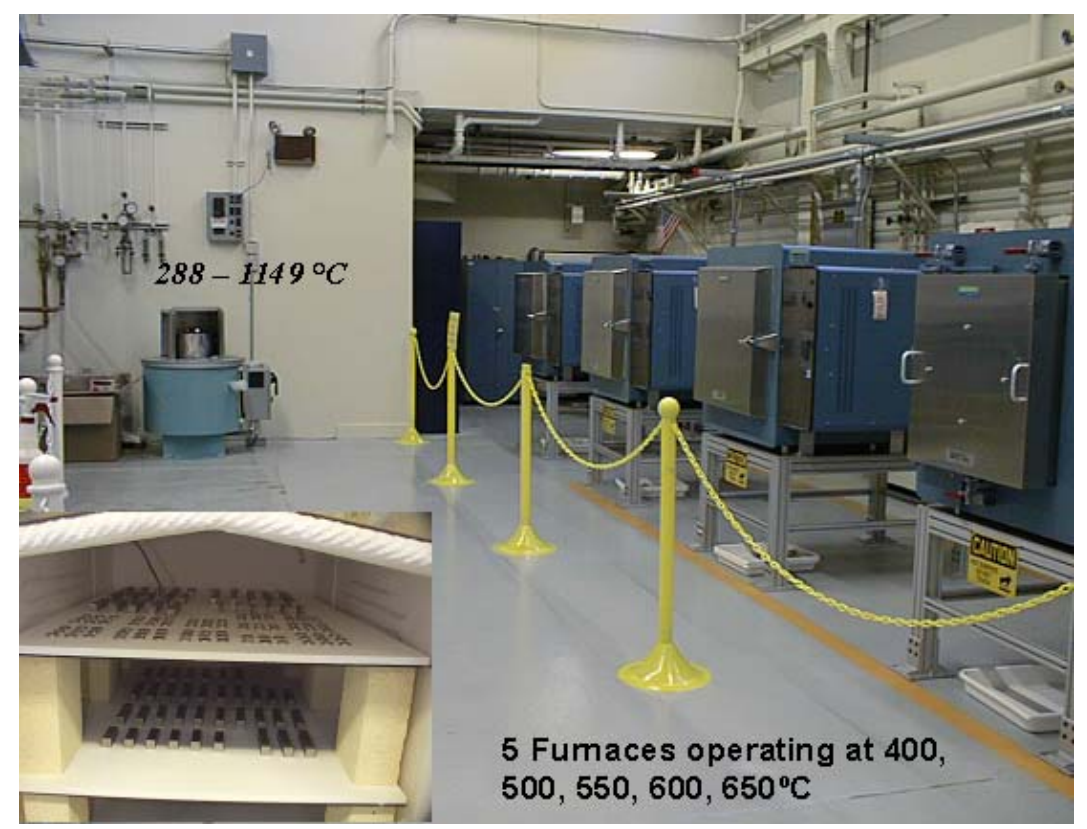

Figure 2.1. High Temperature Aging and Salt Bath Facilities for heat treating Alloy 22 base metal and welds. 

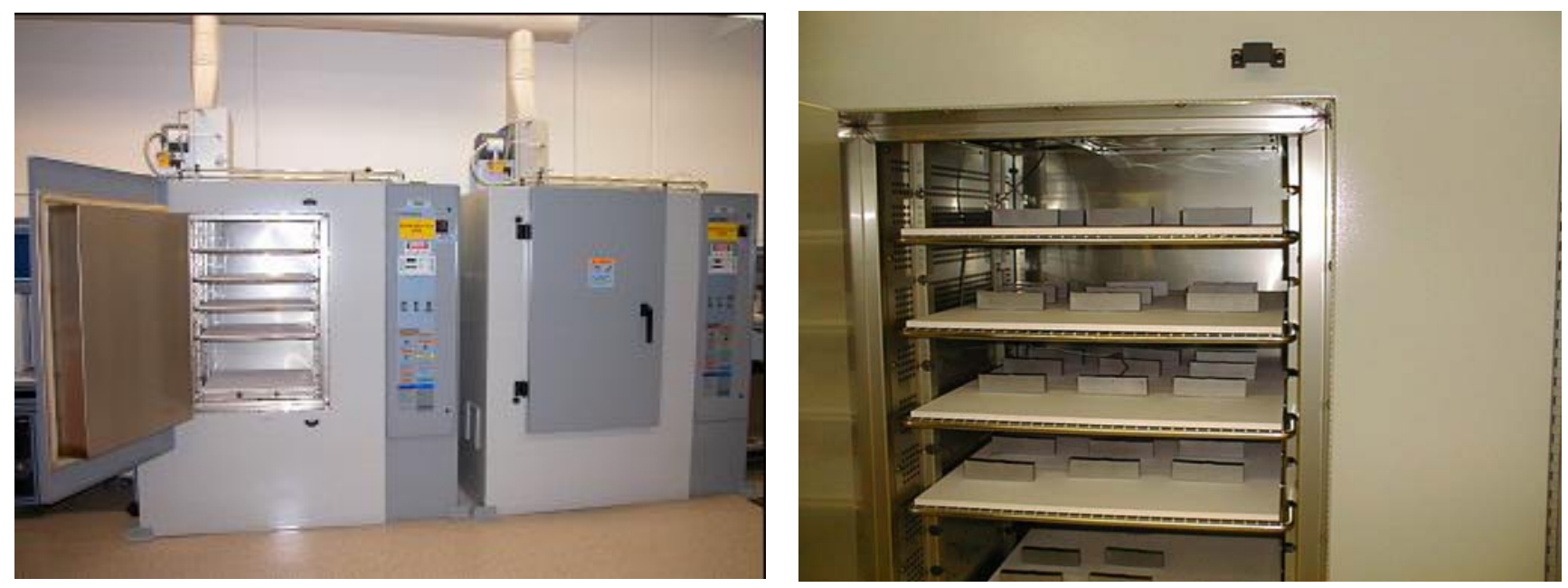

Figure 2.2. Low Temperature Aging Facility for long term aging (20 years) of Alloy 22 base metal and welds at $200^{\circ} \mathrm{C}$ and $300^{\circ} \mathrm{C}$. 


\section{Solution Annealing Studies of Alloy 22 Thick Welds}

\subsection{Methods}

\subsubsection{TCP Phase Quantification and Mapping}

Backscatter electron imaging (described in Section 1.2.1) was used to identify the presence of TCP phases in polished specimens. Due to weld symmetry, only half of the weld (i.e. one "U") was studied for each of the specimens (see Figure 3.1.1.1). This imaging technique was used to:

1. Determine the volume fraction of TCP phases present in the weld, and

2. Map the fusion zones of the as-welded and solution annealed specimens.

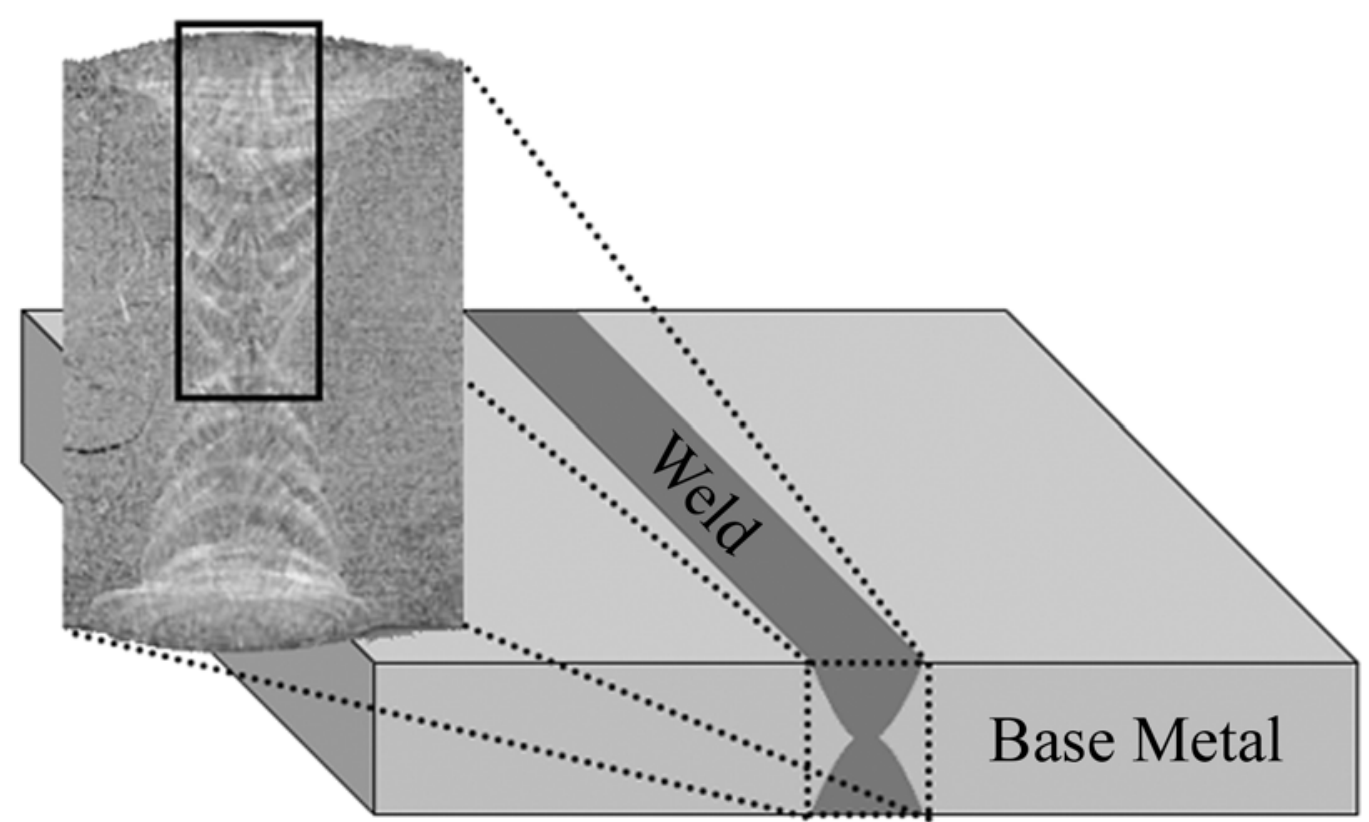

Figure 3.1.1.1. Schematic of weld cross-section showing region of weld examined (black box).

For TCP phase quantification, approximately 40 micrographs were collected at a magnification of 1500X within the top $4 \mathrm{~mm}$ of the weld at regular intervals for each specimen. Imaging was restricted to this weld region because it is the most pertinent to material performance from a corrosion point of view. It is also likely to contain the greatest amount of solute. Image analysis was then performed, yielding an area fraction for the TCP phase (white) portion of each image. The average area fraction of TCP phases in each specimen can be determined from all micrographs measured. Since the images were obtained on a regularly spaced grid, the volume fraction of TCP phases is equal to the measured area fraction.

The fusion zones of the as-welded specimen and the specimen that was solution annealed at $1121^{\circ} \mathrm{C}$ for 20 minutes were mapped. This was performed by collecting 880 micrographs (for each specimen) and stitching them together to form a collage. The collage layout consisted of 44 rows and 20 columns, with the first row at the top of the weld (last weld pass), and the last row near the center of the weld (first weld pass). The individual micrographs were imaged at 500X, which yielded a field of view of approximately $511 \mu \mathrm{m}$ by $441 \mu \mathrm{m}$ for each micrograph. To eliminate 
the chance of overlap, neighboring images were separated by a stage translation of $520 \mu \mathrm{m}$ and $450 \mu \mathrm{m}$ in the $\mathrm{x}$ and $\mathrm{y}$ directions, respectively. The total area covered during the imaging of both specimens was $10.4 \mathrm{~mm}$ by $19.8 \mathrm{~mm}$.

For each of the two specimens imaged in this manner, two collages were generated. The first was of the micrographs as captured (which allowed the visualization of the complete fusion zone microstructure) while the second was of the micrographs after a grayscale threshold had been applied, yielding a map detailing the locations of the TCP phases within the weld fusion zone. Note: The second collage was limited to the first $75 \%$ of the imaged area (i.e. 33 rows) since the weld fusion zone decreases considerably in size the farther the row is from the top of the weld (see Figure 3.1.1.1.).

\subsubsection{Crystallographic Orientation Mapping}

EBSD (described in Section 1.2.2) was used in scanning each specimen to map the microstructure and determine the crystallographic texture of the fusion zones after solution annealing. Due to the size of the area of interest, a combination of beam and stage translations were used during the scans. Data were collected on a square grid, with grid step sizes of $12 \mu \mathrm{m}$ to $30 \mu \mathrm{m}$ (depending on the specimen's grain size) and typically covered an area of approximately $9 \mathrm{~mm}$ by $20 \mathrm{~mm}$. In order to align the EBSD scans with the micrograph collages for the as-welded specimen (and the specimen annealed at $1121^{\circ} \mathrm{C}$ for 20 minutes) two fiducial marks (one at either end of the weld fusion zone) were used.

\subsubsection{Cyclic Polarization Tests}

Specimens were set up in a prism crevice assembly (PCA) (Figure 3.1.3.1). The set-up is based on using crevice formers described by the American Society for Testing and Materials (ASTM) in ASTM G 48, "Standard Test Methods for Pitting and Crevice corrosion resistance of Stainless Steels and Related Alloys by Use of Ferric Chloride Solution". In addition to the Alloy 22 specimen, the PCA set-up consists of ceramic crevice formers and titanium grade 2 bolts, nuts and washers. A layer of polytetrafluoroethylene (PTFE) tape was inserted between the crevice formers and the specimens in order to fill any microvoids and create reproducibly tight crevices. The surface of the titanium bolt was insulated from the specimen using polyolefin shrink fit tubing. The surfaces on the PCA specimens were ground to 600 grit finish using SiC paper after solution annealing, to eliminate the oxide layer that forms during solution annealing.

Electrochemical testing was conducted using a three electrode setup with a saturated silver/silver chloride (SSC) reference electrode and a platinum counter electrode measuring roughly $40 \mathrm{~cm}^{2}$ in surface area. The reference electrode was cooled using a cooling jacket with flowing water maintained at 5 to $12^{\circ} \mathrm{C}$. A water cooled condenser was also used to minimize water vapor loss. Solutions were deaerated using nitrogen gas flowing at a rate of 50 to $100 \mathrm{cc}$ per minute. Nitrogen escaping from the condenser outlet was bubbled through water in order to avoid any backflow of oxygen from the air. 


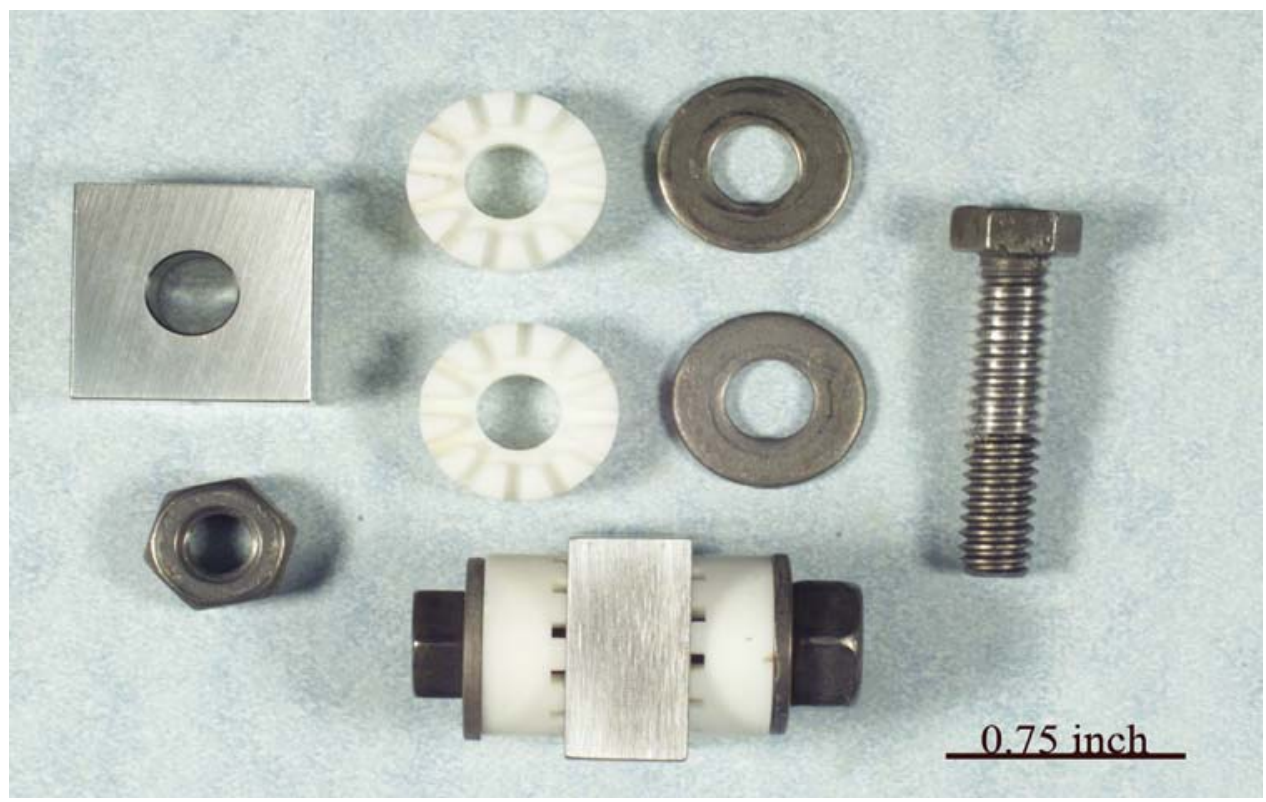

Figure 3.1.3.1. Prism Crevice Assembly (PCA) specimen set up consisting of the Alloy 22 prism, titanium nut, ceramic crevice formers, titanium washers and a titanium bolt. Specimen is shown in the as-received, non-annealed condition.

For each specimen tested, three different electrochemical tests were conducted. First, a twenty-four hour monitoring of the open circuit potential $\left(E_{\text {corr }}\right)$ was done. Immediately following this, a series of polarization resistance tests were performed from which passive corrosion rates were calculated. For the passive corrosion rate calculations, tafel slopes of $0.12 \mathrm{~V}$ per decade and equivalent weights of $23.28 \mathrm{~g} / \mathrm{mol}$ were assumed. Finally a cyclic potentiodynamic polarization (CP) test was performed. The CP scans started at approximately $100 \mathrm{mV}$ below the corrosion potential $\left(E_{\text {corr }}\right)$ and continued until a current density of $5 \mathrm{mAcm}^{-2}$ or a maximum voltage reading of up to $1 \mathrm{~V}$ (SSC) was reached before the scan was reversed. The scan rate used for the forward and reverse sweeps was $0.1667 \mathrm{mVs}^{-1}$.

Two different solutions were used for testing. These were 1 molar $(\mathrm{M}) \mathrm{NaCl}$ and 6 molal $(\mathrm{m})$ $\mathrm{NaCl}+0.9$ molal $(\mathrm{m}) \mathrm{KNO}_{3}$. Specimens were tested in $1 \mathrm{M} \mathrm{NaCl}$ at $90^{\circ} \mathrm{C}$, and in $6 \mathrm{~m} \mathrm{NaCl}+0.9$ $\mathrm{m} \mathrm{KNO}_{3}$ at $100^{\circ} \mathrm{C}$. Sodium chloride and potassium nitrate used to prepare the electrolytes met reagent grade purity requirements set by the American Chemical Society (ACS).

Cyclic polarization data was analyzed for breakdown potential $\left(E_{20}\right)$ and for repassivation potential $\left(E_{r 1}\right) . E_{20}$ is the potential where current density first reaches $2 \times 10^{-5} \mathrm{Acm}^{-2}\left(20 \mu \mathrm{Acm}^{-2}\right)$ on the forward anodic scan of the polarization curve. It is a measure of resistance to initiation of localized corrosion. $E_{r 1}$ is the potential where a decaying current density reaches $1 \times 10^{-6} \mathrm{Acm}^{-2}(1$ $\mu \mathrm{Acm}^{-2}$ ) on the reverse scan of the polarization curve, that is, below the chosen potential. The current density consistently remains below a current density of $1 \mu \mathrm{Acm}^{-2}$ in the anodic portion of the reverse scan. The repassivation potential $E_{r 1}$ is a measure of how easily a specimen repassivates once localized corrosion has initiated, and represents the potential below which self sustaining localized corrosion is not expected to occur. $E_{r 1}$ is only considered to be a true measure of repassivation if it occurs at a lower potential than the breakdown potential $\left(E_{20}\right.$ in this study). 


\subsection{Results and Discussion}

\subsubsection{Phase Stability and Recrystallization}

The results of the TCP volume fraction measurements are listed in Table 3.2.1.1. It can be seen that TCP phases are present in only three of the seventeen specimens, in the as-welded and specimens solution annealed for 20 minutes at $1075^{\circ} \mathrm{C}$ and $1121^{\circ} \mathrm{C}$, respectively. Since the volume fractions measured were $<1 \%$ and the TCP phases were inhomogeneously dispersed, the relative error associated with the values is high. Therefore, the values determined should only be used as an indication of the presence of TCP phases. It is important to note that for the specimens with zero volume fractions, the lack of TCP phase observations does not fully eliminate the possibility of their existence, rather it indicates that if any are present, they are significantly smaller than $0.25 \mu \mathrm{m}$ (the resolution of the SEM).

Figures 3.2.1.1 (a) and 3.2.1.1 (b) illustrate the micrograph collages generated for the as-welded specimen and the specimen annealed at $1121^{\circ} \mathrm{C}$ for 20 minutes, respectively. Figures 3.2.1.2 (a) and 3.2.1.2 (b) are the corresponding collages after a threshold and inversion (so that the TCP phases appear black instead of white) had been applied to the micrographs, showing the location of the TCP phases. It is apparent that the location of the TCP phases follows the weld pass geometry. It can also be seen that while the TCP phase distribution is spatially homogeneous (at the apparent length scale) near the top of the weld, there is a distinct banding structure in the first few weld passes. Note: In Figures 3.2.1.2 (a) and 3.2.1.2 (b) the TCP phase sizes in the images were artificially coarsened for clarity, and the particle sizes observed are not to scale.

Figure 3.2.1.3 presents the results of the EBSD scans for the as-welded specimen as well as the specimens annealed for 20 minutes at all four temperatures as color-coded Inverse Pole Figure (IPF) maps. The colors correspond to the crystallographic directions parallel to the specimen [010] axis (toward the top of the page). This direction was selected since it is parallel (and opposite) to the heat flow axis present during the welding process. It can also be seen in Figures 3.2.1.3 (b), (c), (d), and (e) that while the specimens treated at $1075^{\circ} \mathrm{C}$ and $1121^{\circ} \mathrm{C}$ are still in the process of recrystallization, the specimen treated at $1200^{\circ} \mathrm{C}$ appears fully recrystallized while the specimen treated at $1300^{\circ} \mathrm{C}$ possesses coarsened grains. The recrystallization behavior in the $1075^{\circ} \mathrm{C}$ and $1121^{\circ} \mathrm{C}$ specimens is closely related to the weld pass geometry.

Results of the observed microstructure are also listed in Table 3.2.1.1 for each solution annealing condition. Full recrystallization (> 95\%) of the columnar dendrites in the fusion zone was observed in the specimens annealed for 168 hours at $1075^{\circ} \mathrm{C}, 24$ hours at $1121^{\circ} \mathrm{C}$, and 20 minutes at $1200^{\circ} \mathrm{C}$. Backscattered electron SEM micrographs of these specimens are shown in Figure 3.2.1.4. In the specimen aged at $1300^{\circ} \mathrm{C}$ full recrystallization must have occurred well before 20 minutes since rapid grain growth and coarsening behavior were observed at the 20 minute mark. Also observed was significant grain coarsening near the fusion zone boundary of the specimens annealed at $1075^{\circ} \mathrm{C}$ for 168 hours, $1121^{\circ} \mathrm{C}$ for durations of 72 hours and greater, $1200^{\circ} \mathrm{C}$ for durations of 24 hours and greater, and for all the specimens annealed at $1300^{\circ} \mathrm{C}$. 
Table 3.2.1.1. TCP Phase Volume Fractions and Recrystallization Behavior of Solution Annealed Alloy 22 Welds (Source: DTN LL050303812251.030)

\begin{tabular}{|c|c|c|c|c|}
\hline $\begin{array}{c}\text { Specimen } \\
\text { Number }\end{array}$ & $\begin{array}{c}\text { Annealing } \\
\text { Temperature }\end{array}$ & $\begin{array}{l}\text { Annealing } \\
\text { Duration }\end{array}$ & $\begin{array}{c}\text { Volume } \\
\text { Fraction (\%) }\end{array}$ & Recrystallization Behavior \\
\hline 1 & None & None & $0.11 \pm 0.09$ & Not Applicable \\
\hline 2 & $1075^{\circ} \mathrm{C}$ & 20 minutes & $0.53 \pm 0.42$ & Small amount near weld toe \\
\hline 3 & $1075^{\circ} \mathrm{C}$ & 24 hours & 0 & $\begin{array}{l}\text { Banding at weld pass interfaces; grain } \\
\text { growth at root pass region }\end{array}$ \\
\hline 4 & $1075^{\circ} \mathrm{C}$ & 72 hours & 0 & $\begin{array}{l}\text { Grain coarsening near weld toe; } \\
\text { recrystallization throughout weld, except } \\
\text { near weld top }\end{array}$ \\
\hline 5 & $1075^{\circ} \mathrm{C}$ & 168 hours & 0 & $\begin{array}{l}\text { Fully recrystallized; abnormal grain growth in } \\
\text { root pass region and near fusion zone } \\
\text { boundary }\end{array}$ \\
\hline 6 & $1121^{\circ} \mathrm{C}$ & 20 minutes & $0.24 \pm 0.15$ & $\begin{array}{l}\text { Recrystallization at root pass region and } \\
\text { banding at weld pass interfaces }\end{array}$ \\
\hline 7 & $1121^{\circ} \mathrm{C}$ & 24 hours & 0 & $\begin{array}{c}\text { Fully recrystallized; large grains at root pass } \\
\text { region and near base metal }\end{array}$ \\
\hline 8 & $1121^{\circ} \mathrm{C}$ & 72 hours & 0 & $\begin{array}{l}\text { Grain growth in fusion zone; abnormal grain } \\
\text { growth near fusion zone boundary }\end{array}$ \\
\hline 9 & $1121^{\circ} \mathrm{C}$ & 168 hours & 0 & $\begin{array}{l}\text { Grain coarsening in fusion zone; abnormal } \\
\text { grain growth near fusion zone boundary }\end{array}$ \\
\hline 10 & $1200^{\circ} \mathrm{C}$ & 20 minutes & 0 & $\begin{array}{l}\text { Fully recrystallized; homogeneous grain } \\
\text { sizes observed throughout }\end{array}$ \\
\hline 11 & $1200^{\circ} \mathrm{C}$ & 24 hours & 0 & $\begin{array}{l}\text { Grain growth in fusion zone; abnormal grain } \\
\text { growth near fusion zone boundary }\end{array}$ \\
\hline 12 & $1200^{\circ} \mathrm{C}$ & 72 hours & 0 & Coarsened grains throughout \\
\hline 13 & $1200^{\circ} \mathrm{C}$ & 168 hours & 0 & Coarsened grains throughout \\
\hline 14 & $1300^{\circ} \mathrm{C}$ & 20 minutes & 0 & Abnormal grain growth in fusion zone \\
\hline 15 & $1300^{\circ} \mathrm{C}$ & 24 hours & 0 & Coarsened grains throughout \\
\hline 16 & $1300^{\circ} \mathrm{C}$ & 72 hours & 0 & Coarsened grains throughout \\
\hline 17 & $1300^{\circ} \mathrm{C}$ & 168 hours & 0 & Coarsened grains throughout \\
\hline
\end{tabular}



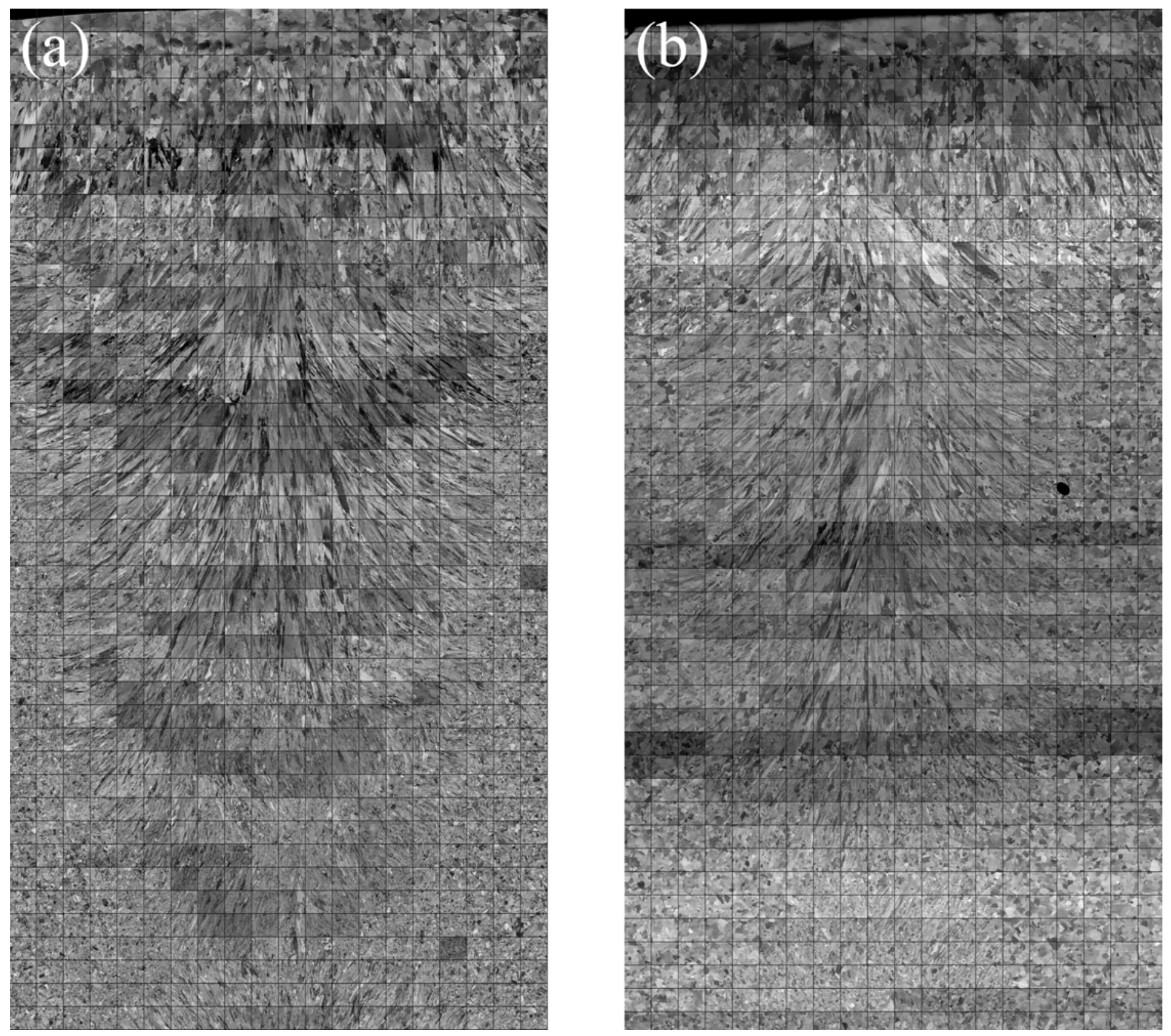

Figure 3.2.1.1. Collages created by joining 880 ( 20 columns $x 44$ rows) SEM backscattered electron micrographs of the (a) as-welded specimen and (b) the specimen solution annealed at $1121^{\circ} \mathrm{C}$ for 20 minutes. (Source: DTN LL050304012251.032) 

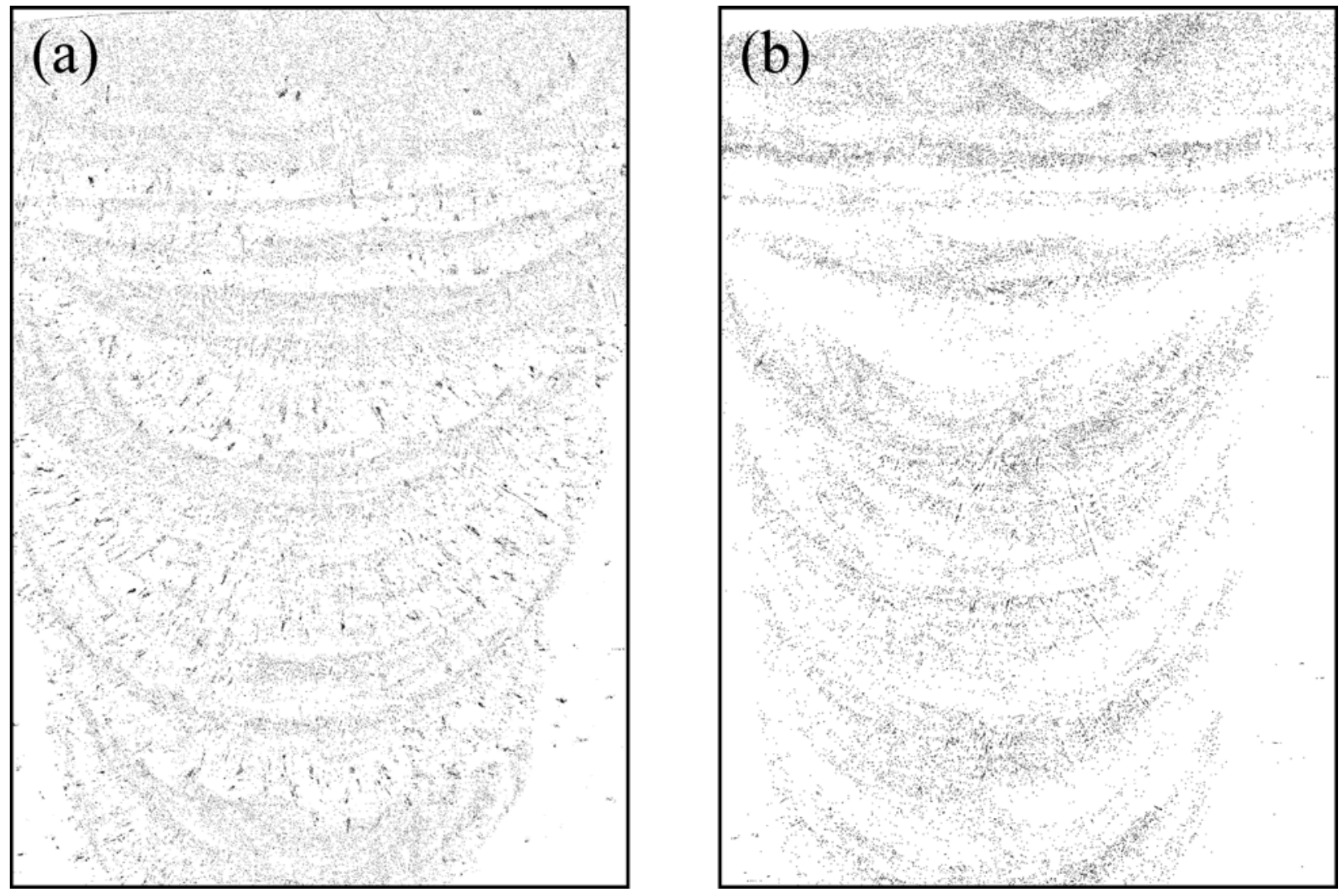

Figure 3.2.1.2. Location of TCP phases in the (a) as-welded specimen and (b) the specimen annealed at $1121^{\circ} \mathrm{C}$ for 20 minutes as determined from the collages shown in Figure 3.2.1.1. NOTE: The images only represent the top $3 / 4$ of the collages shown in Figure 3.2.1.1 and that the sizes of the TCP phases have been coarsened for clarity. (Source: DTN LL050304012251.032) 

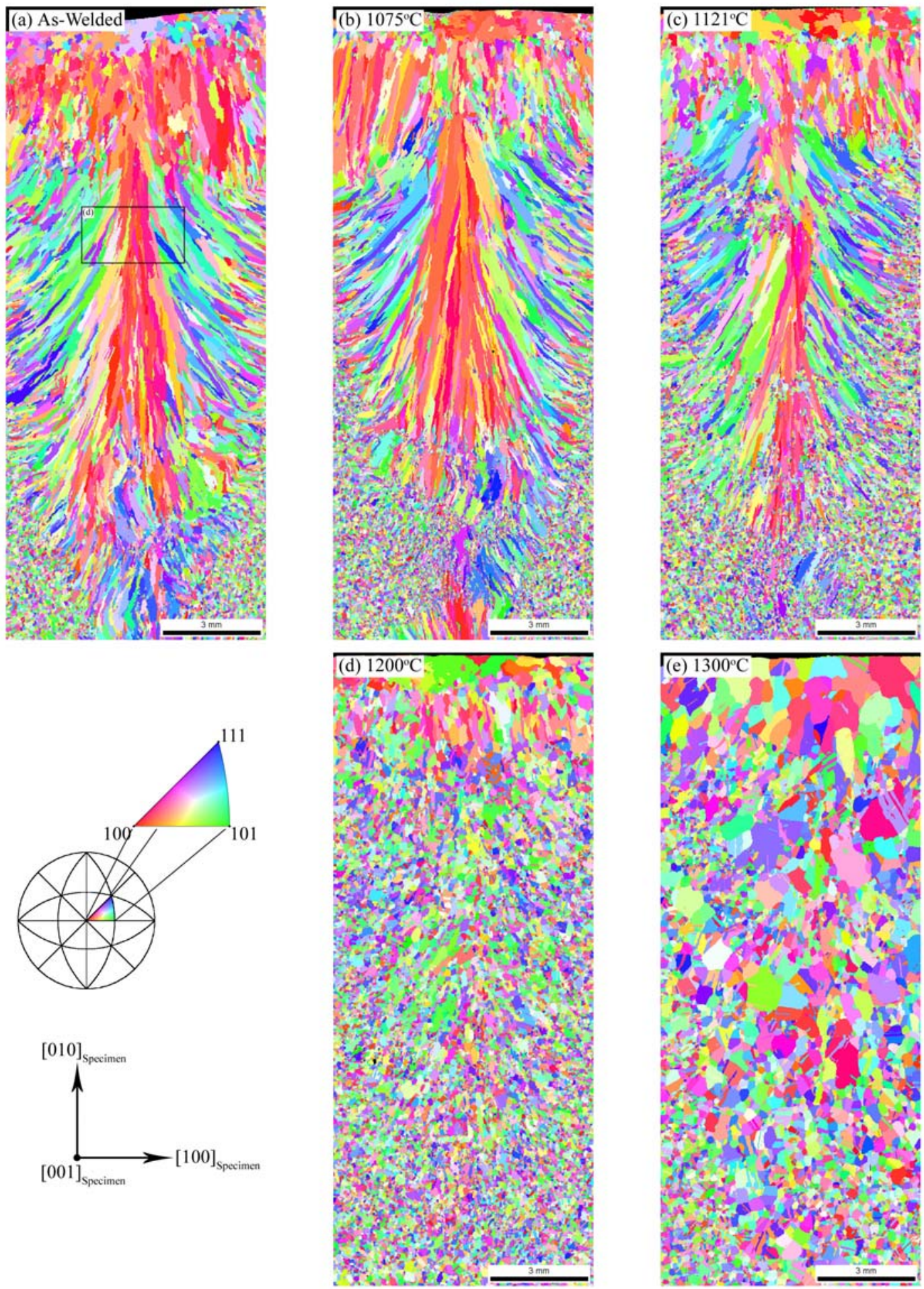

Figure 3.2.1.3. Inverse Pole Figure maps of (a) the as-welded specimen and the specimens annealed for 20 minutes at (b) $1075^{\circ} \mathrm{C}$, (c) $1121^{\circ} \mathrm{C}$, (d) $1200^{\circ} \mathrm{C}$, and (e) $1300^{\circ} \mathrm{C}$. The colors represent the crystallographic plane normals parallel and opposite the heat flow direction during solidification (toward the top of the page). (Source: DTN LL050303612251.028) 

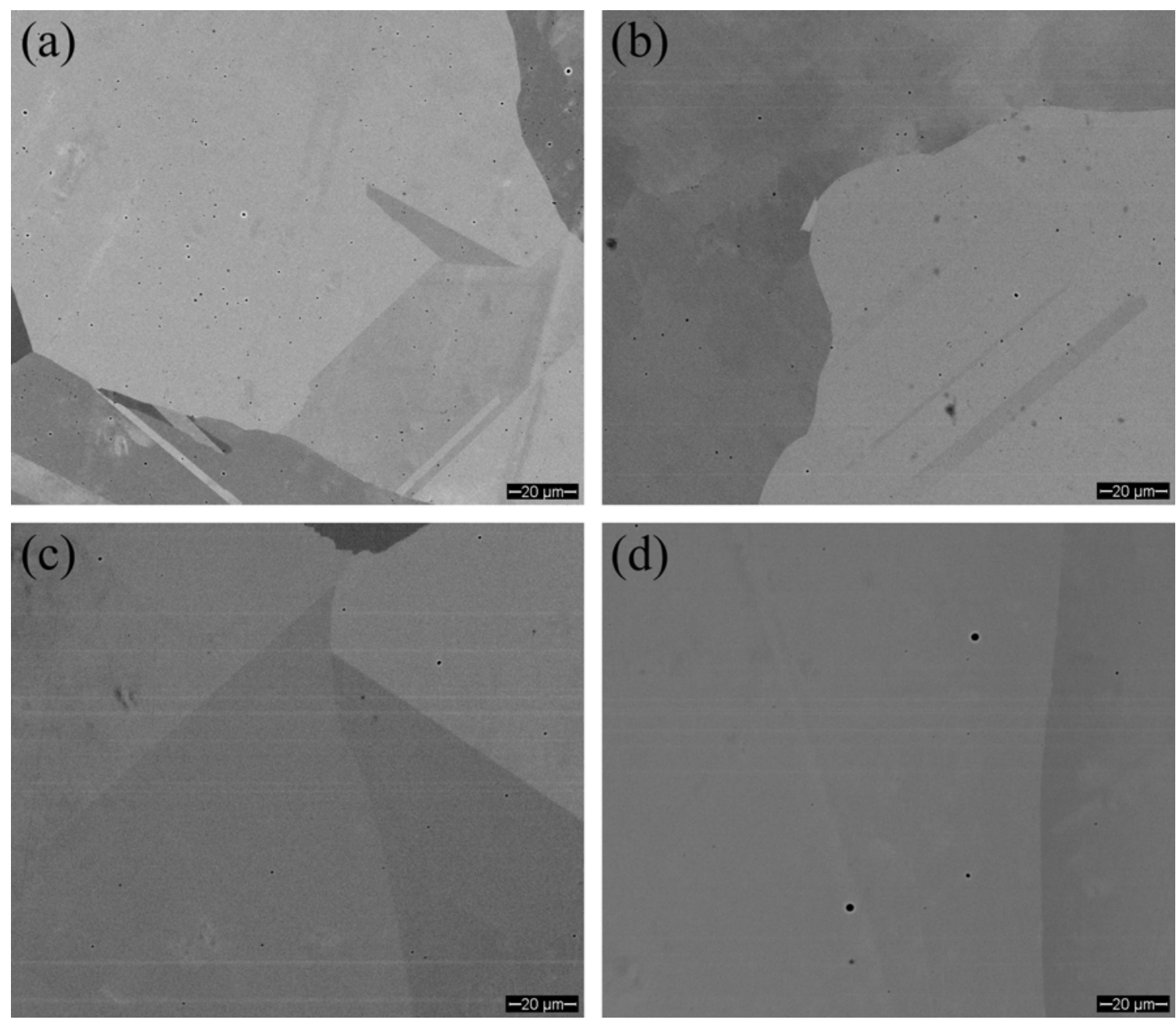

Figure 3.2.1.4. Backscattered electron SEM micrographs (imaged at 1500X) of specimens fully recrystallized. Specimens were solution annealed for (a) 168 hours at $1075^{\circ} \mathrm{C}$, (b) 24 hours at $1121^{\circ} \mathrm{C}$, (c) 20 minutes at $1200^{\circ} \mathrm{C}$, and (d) 20 minutes at $1300^{\circ} \mathrm{C}$. (Source: DTN LL050303712251.029)

\subsubsection{Corrosion Behavior}

\section{Data Terms Defined:}

Corrosion Potential $\left(E_{\text {corr }}\right)$ or Open Circuit Potential $(O C P)$ - Specimen surface potential at which oxidation and reduction reactions are occurring at equal rates. This is the potential that the material develops in response to the environment to which it is exposed. This response depends on the material's surface condition and will evolve with time. Measured vs. $\mathrm{Ag} / \mathrm{AgCl}$ reference electrode in these experiments.

Corrosion Rate - Relative measure of the general corrosion rate at the corrosion potential and is determined using the polarization resistance technique. Assumes that general dissolution is primarily occurring on the specimen surface.

$E_{20}$ - Potential where current density first reaches $20 \times 10^{-6} \mathrm{Acm}^{-2}$ on the forward scan of the cyclic potentiodynamic polarization (CPP) curve. $E_{20}$ is generally associated with resistance to initiation of localized corrosion; higher values normally represent higher resistance to initiation. 
$E_{b d}$ - Potential where current density makes its first permanent increase away from the passive behavior region of the CPP curve on the forward scan. This is referred to as the breakdown potential. $E_{b d}$ is another measure of resistance to localized corrosion initiation (higher values normally represent higher resistance to initiation).

$E_{r 1}$ - Potential where current density first reaches $1 \times 10^{-6} \mathrm{Acm}^{-2}$ on the reverse scan of the polarization curve. $E_{r 1}$ is a measure of ability to repassivate (heal) localized corrosion that has been initiated (higher $\mathrm{E}_{\mathrm{r} 1}$ values normally represent a higher ability to repassivate).

$E_{\text {rco }}$ - Potential where reverse scan and forward scan of the CPP curve intersect (or cross over). $\mathrm{E}_{\mathrm{rco}}$ is another measure of ability to repassivate (higher $\mathrm{E}_{\mathrm{rco}}$ values represent a higher ability to repassivate).

\section{$1 \mathrm{M} \mathrm{NaCl}$ at $90^{\circ} \mathrm{C}$ :}

1. The specimen surfaces were ground in order to remove the oxide after the annealing process.

2. Cyclic potentiodynamic polarization (CPP) curves for the different annealing conditions are shown in Figure 3.2.2.1. The CPP curves for all the specimens, except the $1300^{\circ} \mathrm{C}$ specimen, showed hysteresis, which is indicative of localized corrosion degradation. The amount of hysteresis for the as-welded, $1075^{\circ} \mathrm{C}$, and $1121^{\circ} \mathrm{C}$ specimens is almost the same. The CPP curve for the $1200^{\circ} \mathrm{C}$ specimen showed a smaller amount of hysteresis. The CPP curves for $1300^{\circ} \mathrm{C}$ specimens did not show hysteresis.

3. 24 hour corrosion potential data and corrosion rate data indicate that the solution annealed specimens show slightly better passive corrosion resistance than the non-annealed specimens, as shown in Figures 3.2.2.2 (a) and (b), respectively.

4. Breakdown ( $E_{20}$ and $\left.E_{\text {crit }}\right)$ potentials for all specimens except those annealed at $1300^{\circ} \mathrm{C}$ are similar, as seen in Figures 3.2.2.2 (c) and (d). The potentials for the $1300^{\circ} \mathrm{C}$ annealed specimens are significantly lower.

5. All specimens show similar repassivation potentials $\left(E_{r 1}\right)$ as seen in Figure 3.2.2.2 (e). Also the crossover potentials $\left(E_{\mathrm{rco}}\right)$ are similar for all specimens except the $1300^{\circ} \mathrm{C}$ annealed specimens. Only one of the $1300^{\circ} \mathrm{C}$ specimens had a cross over potential.

6. Optical microscope examination indicated that all specimens tested in $1 \mathrm{M} \mathrm{NaCl}$ at $90^{\circ} \mathrm{C}$ showed localized corrosion to some degree. The specimens annealed at the highest temperatures had the lowest area of localized corrosion and appeared to have shallower crevice attack (this was not confirmed quantitatively).

The post-test optical examination of the specimens indicates that solution annealing has some beneficial effect on the localized corrosion susceptibility of Alloy 22 in this electrolyte. The electrochemical data is more ambiguous. The breakdown potentials are similar except for $1300^{\circ} \mathrm{C}$ annealed specimens for which the CPP curves indicate much lower breakdown potentials. This is not consistent with the observation of less corrosion damage with annealing temperature. Additionally, the repassivation potentials $\left(E_{r 1}\right.$ and $\left.E_{r c o}\right)$ are very similar except for the $1300^{\circ} \mathrm{C}$ annealed specimen $\mathrm{E}_{\mathrm{rco}}$ value (from only one curve).

As noted above, the specimens were ground before testing in order to remove the oxide from the annealing process. It is possible that some residual oxide was left on the surface and hence the CPP curves reflect both the localized corrosion susceptibility and the dissolution of the residual oxide. This could explain the very low breakdown potentials for the $1300^{\circ} \mathrm{C}$ specimens where there is a large current increase at relatively low potential (more surface oxidation is 
expected for the higher annealing temperatures). If breakdown does occur at lower potentials then localized corrosion should be evident by stopping the CPP scan at a lower potential.

The combined optical examination and electrochemical characterization do indicate that the annealing process does have a net positive effect on the localized corrosion resistance of Alloy 22 in $1 \mathrm{M} \mathrm{NaCl}$.

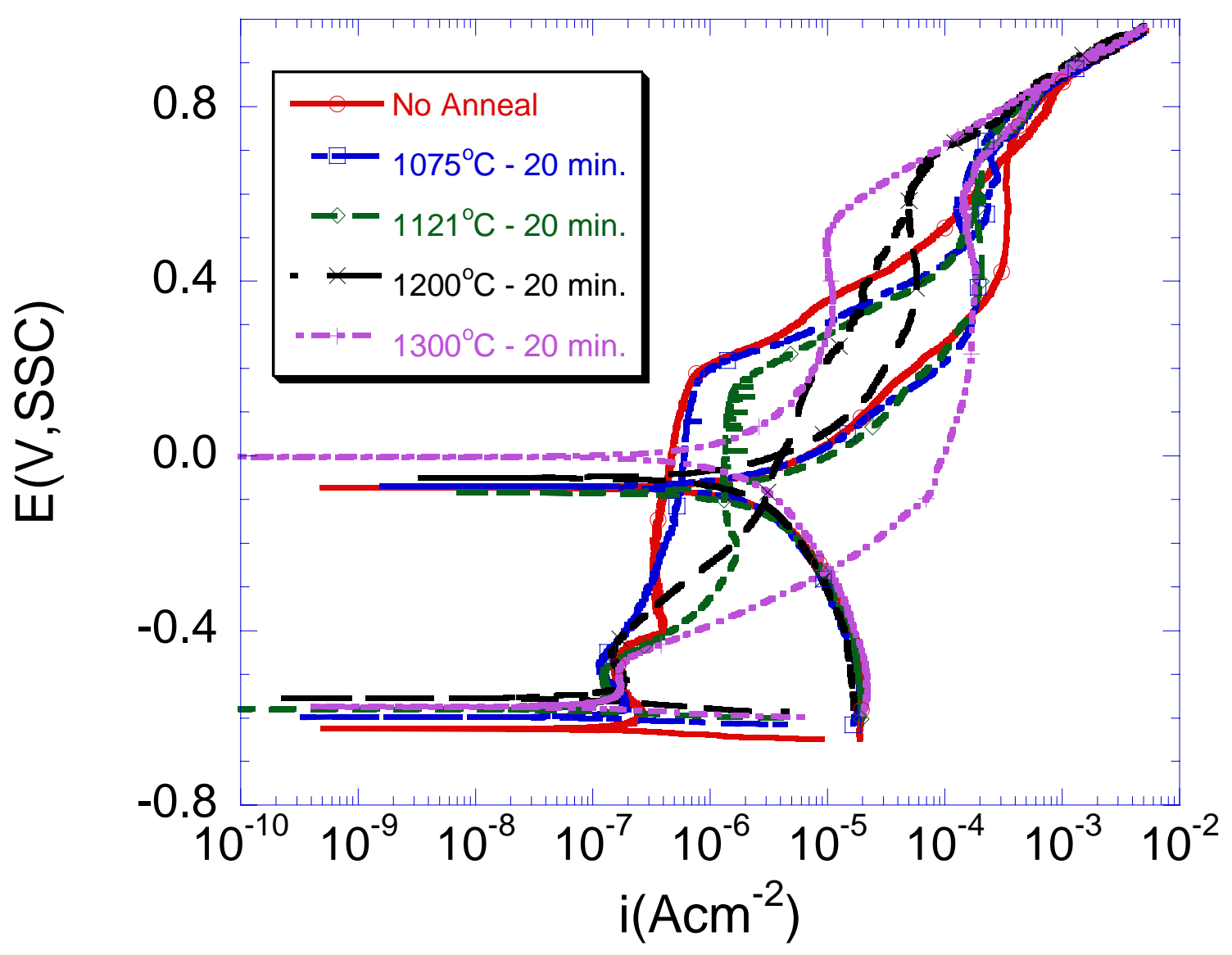

Figure 3.2.2.1. Cyclic polarization curves for specimens non-annealed and solution annealed at $1075,1121,1200$, and $1300^{\circ} \mathrm{C}$ for 20 minutes and tested in $1 \mathrm{M}$ $\mathrm{NaCl}$ at $90^{\circ} \mathrm{C}$. (Source: DTN LL050803712251.036) 

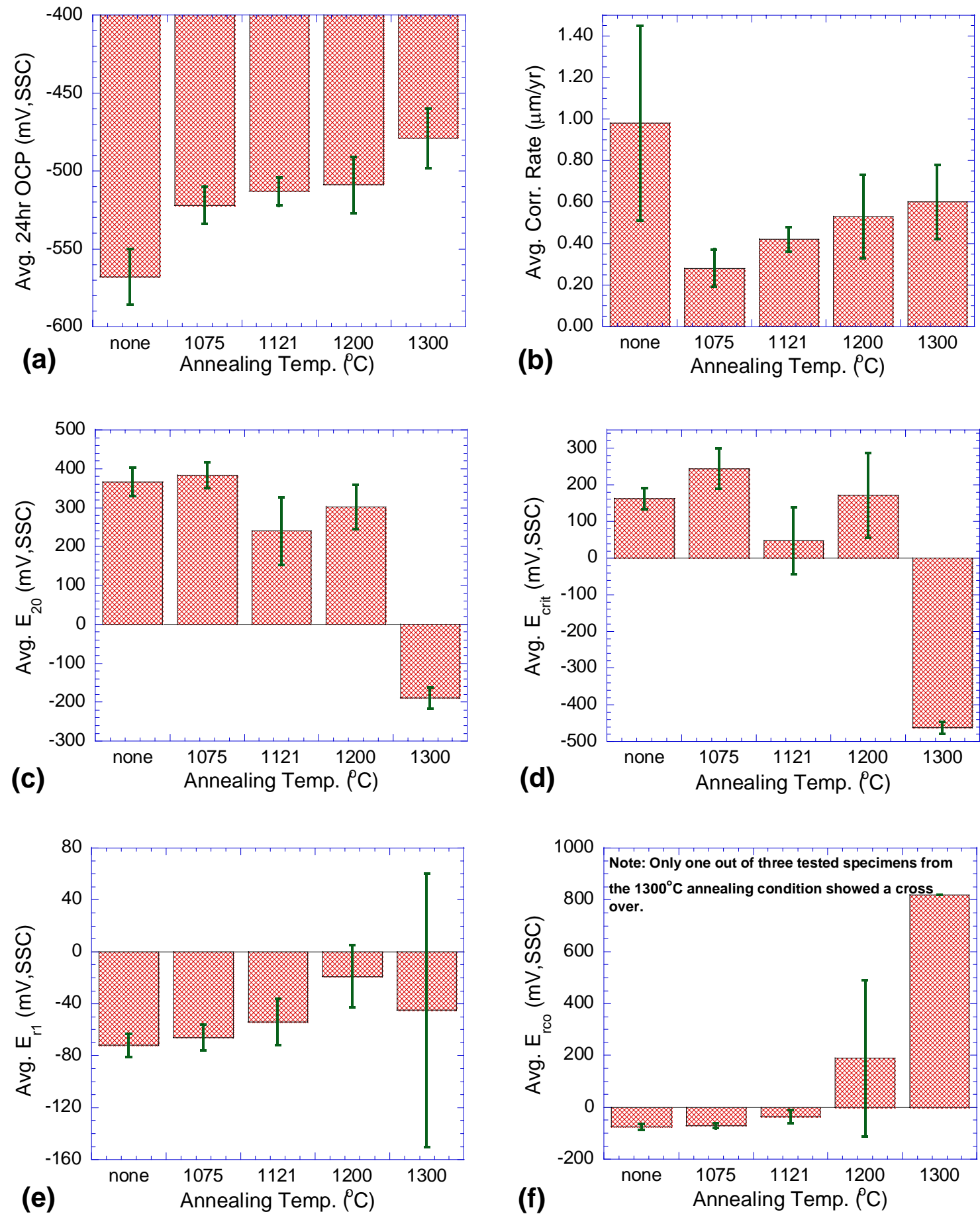

Figure 3.2.2.2. Average values for specimens non-annealed and solution annealed at 1075, 1121,1200 , and $1300^{\circ} \mathrm{C}$ for 20 minutes tested in $1 \mathrm{M} \mathrm{NaCl}$ at $90^{\circ} \mathrm{C}$ of (a) 24 hour corrosion potential, (b) corrosion rate, (c) $E_{20}$, (d) $E_{\text {crit, }}$ (e) $E_{r 1}$, and (f) cross over $\left(E_{\text {rco }}\right)$. (Source: DTN LL050803812251.037) 


\section{$\underline{6 \mathrm{~m} \mathrm{NaCl}+0.9 \mathrm{~m} \mathrm{KNO}_{3}}{ }_{3}$ at $100^{\circ} \mathrm{C}:$}

1. The specimen surfaces were ground in order to remove the oxide after the annealing process.

2. The data for this electrolyte is similar to the data for $1 \mathrm{M} \mathrm{NaCl}$ at $90^{\circ} \mathrm{C}$. Cyclic polarization curves for the 1075 and $1121^{\circ} \mathrm{C}$ annealing conditions show similar hysteresis loops in the as-welded specimens, however there are no discernable hysteresis loops for the 1200 and $1300^{\circ} \mathrm{C}$ specimens (see Figure 3.2.2.3).

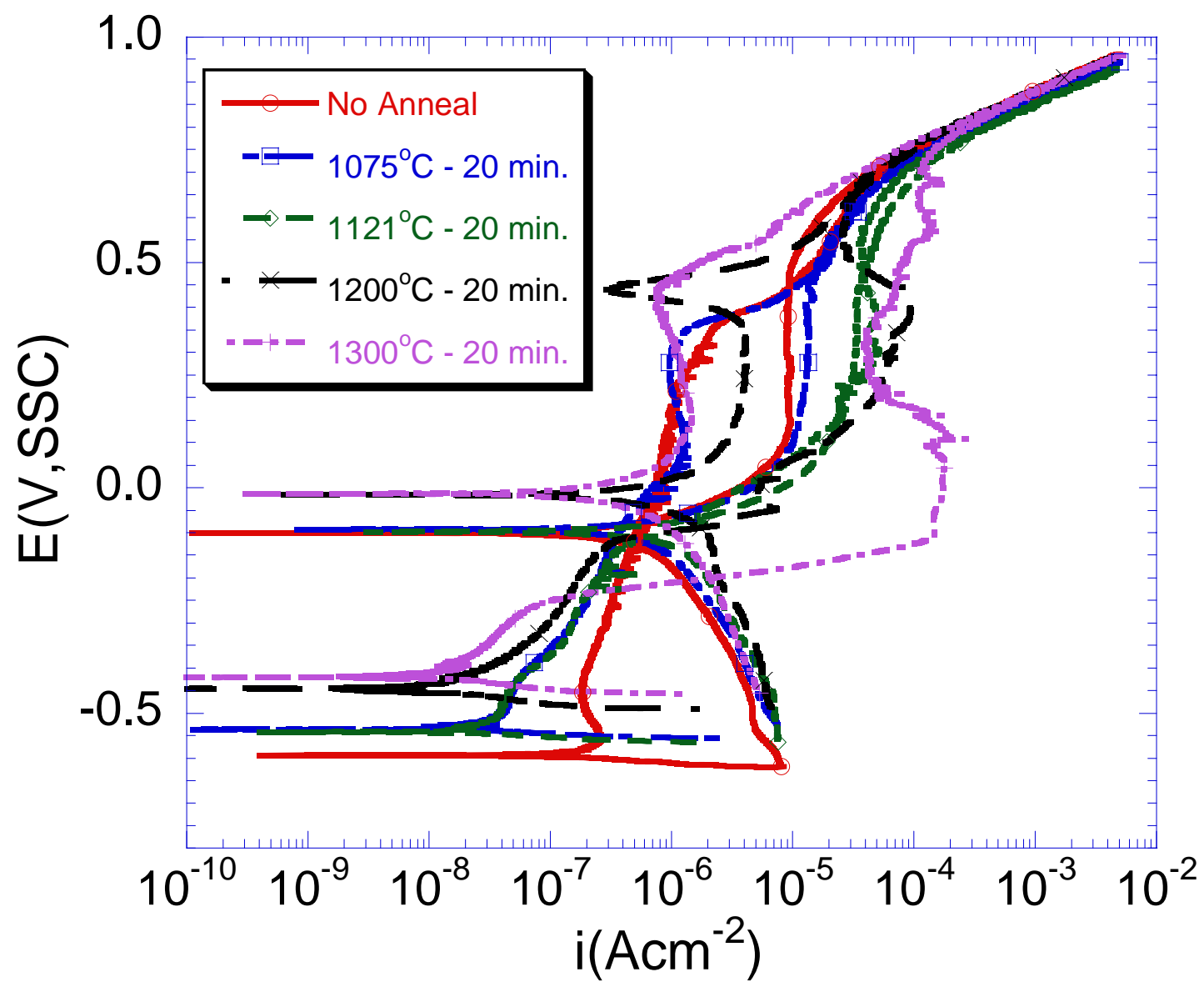

Figure 3.2.2.3. Cyclic potentiodynamic polarization curves in $6 \mathrm{~m} \mathrm{NaCl}+0.9 \mathrm{~m} \mathrm{KNO}$ at $100^{\circ} \mathrm{C}$ for a non-annealed specimen and specimens that were solution annealed at $1075,1121,1200$, and $1300^{\circ} \mathrm{C}$ for 20 minutes. (Source: DTN LL050803712251.036)

3. Corrosion potential data and corrosion rate data indicate that the solution annealed specimens show slightly better passive corrosion resistance than the as-welded specimens as plotted in Figures 3.2.2.4 (a) and (b), respectively.

4. The breakdown potentials $\left(\mathrm{E}_{20}\right.$ and $\left.\mathrm{E}_{\mathrm{bd}}\right)$ for the as-welded and the $1075^{\circ} \mathrm{C}$ specimens are similar, while those for the higher annealing temperatures are much lower (Figures 3.2.2.4 (c) and (d)). 
5. The repassivation potentials for the as-welded and 1075 and $1121^{\circ} \mathrm{C}$ annealed specimens are similar, however $E_{r 1}$ is much larger for the 1200 and $1300^{\circ} \mathrm{C}$ specimens. In fact, they are significantly larger than the breakdown potentials.

6. Optical examination of the specimens tested in $6 \mathrm{~m} \mathrm{NaCl}+0.9 \mathrm{~m} \mathrm{KNO}_{3}$ at $100^{\circ} \mathrm{C}$ showed localized corrosion to some degree (Figure 3.2.2.5). The specimens annealed at the highest temperatures had the lowest area of localized corrosion and appeared to have shallower crevice attack. The specimens tested in this aqueous test solution also showed less localized corrosion overall than specimens tested in $1 \mathrm{M} \mathrm{NaCl}$ at $90^{\circ} \mathrm{C}$.

Overall the effects of solution annealing on Alloy 22 corrosion behavior in $6 \mathrm{~m} \mathrm{NaCl}+0.9 \mathrm{~m}$ $\mathrm{KNO}_{3}$ at $100^{\circ} \mathrm{C}$ are similar to those found for $1 \mathrm{M} \mathrm{NaCl}$ at $90^{\circ} \mathrm{C}$. Visual observations also indicate that the extent of localized corrosion degradation appears to improve with solution annealing. The electrochemical data is ambiguous; breakdown potentials are lower for the higher annealing temperatures, while repassivation potentials are higher.

As noted above, the specimens were ground before testing in order to remove the oxide from the annealing process. It is possible that some residual oxide was left on the surface and hence the CPP curves reflect both the localized corrosion susceptibility and the dissolution of the residual oxide. This could explain the very low breakdown potentials for the 1121,1200 , \& $1300^{\circ} \mathrm{C}$ anneal specimens where there is a large current increase at relatively low potential more surface oxidation is expected for the higher annealing temperature. (These solutions induce more general dissolution due to the higher chloride level than the $1 \mathrm{M} \mathrm{NaCl}$ solution above.) The alternative explanation is that breakdown occurs at lower potentials.

The apparent discrepancy between the breakdown and repassivation potentials for the 1200 and $1300^{\circ} \mathrm{C}$ annealed specimens $\left(E_{r 1}\right.$ greater than $E_{20}$ and $\left.E_{b d}\right)$ could possibly be due to the general dissolution at low potentials obscuring the onset of localized corrosion.

The combined optical examination and electrochemical characterization do indicate that the annealing process does have a net positive effect on the localized corrosion resistance of Alloy 22 in $1 \mathrm{M} \mathrm{NaCl}$. 

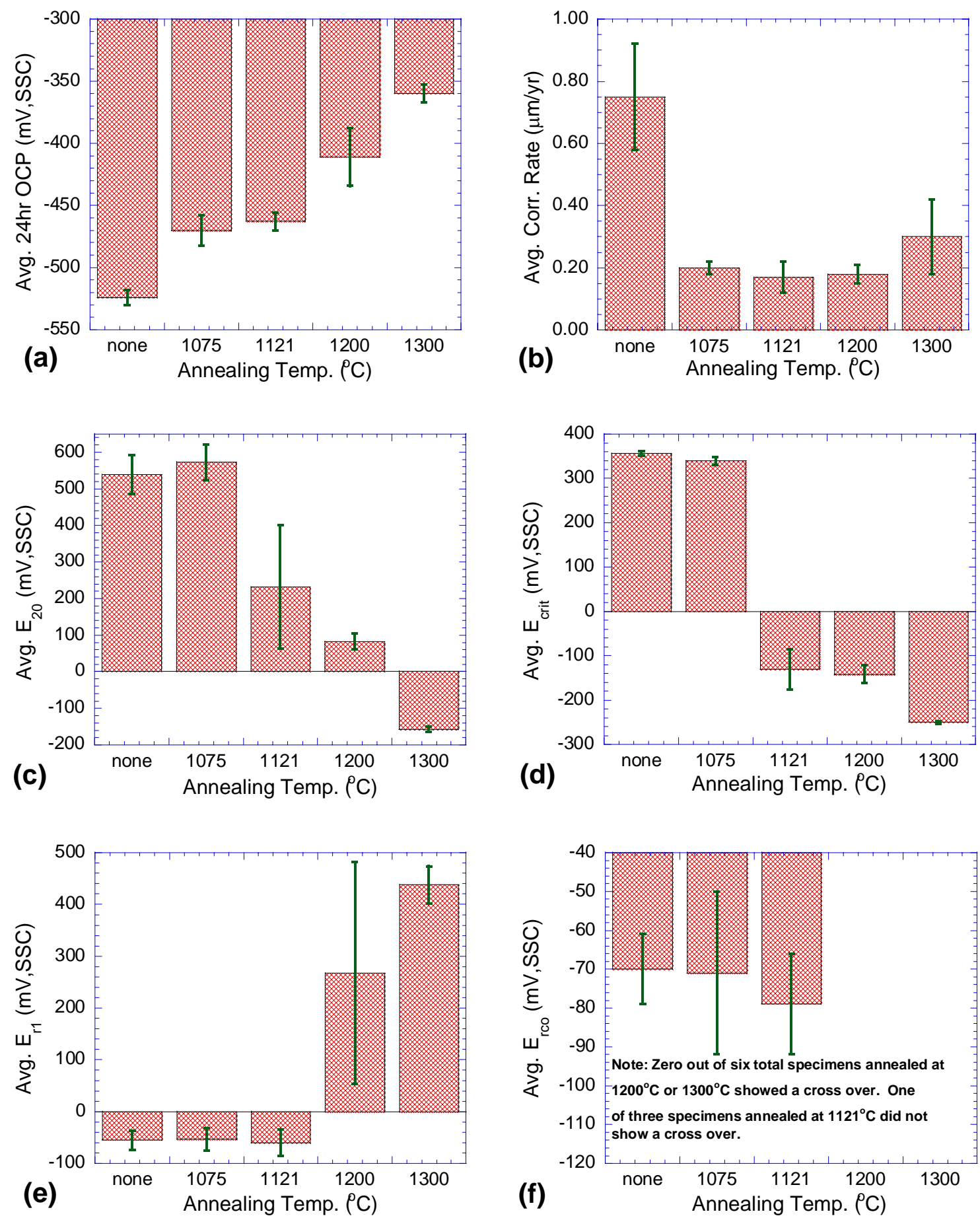

Figure 3.2.2.4. Average values for solution annealed specimens tested in $6 \mathrm{~m} \mathrm{NaCl}+0.9 \mathrm{~m}$ $\mathrm{KNO}_{3}$ at $100^{\circ} \mathrm{C}$ of (a) 24 hour corrosion potential values, (b) corrosion rate, (c) $E_{20}$, (d) $E_{\text {crit, }}$ (e) $E_{r 1}$, and (f) cross over $\left(E_{r c o}\right)$. (Source: DTN LL050803812251.037) 


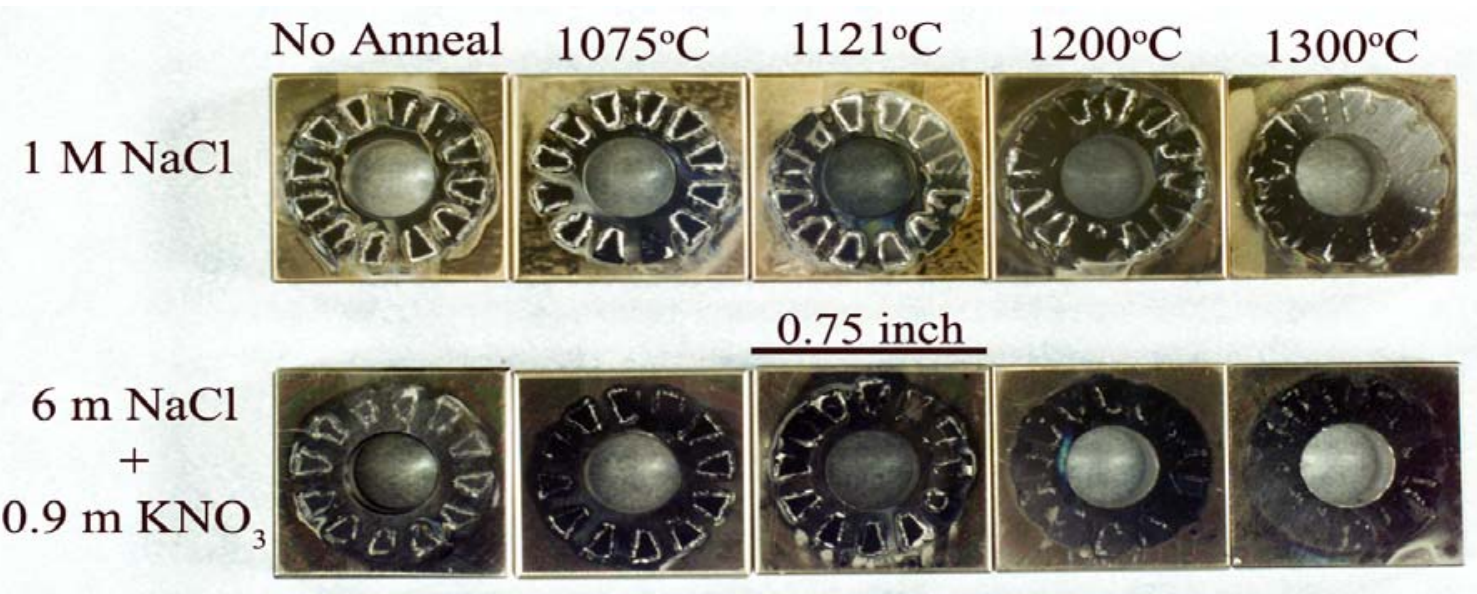

Figure 3.2.2.5. Specimens tested in $1 \mathrm{M} \mathrm{NaCl}$ at $90^{\circ} \mathrm{C}$ (top row) and $6 \mathrm{~m} \mathrm{NaCl}+0.9 \mathrm{~m} \mathrm{KNO}$ at $100^{\circ} \mathrm{C}$ (bottom row). Vertical position of specimen designates its heat treatment (see above each column). Welds are oriented vertically through each specimen. (Source: DTN LL050803712251.036)

\subsection{Summary}

Since the primary focus of the solution annealing treatment from a microstructural point of view is the dissolution of TCP phases and homogenization of the microstructure, two aspects of the results need to be considered; the extent of TCP phase dissolution and the extent of fusion zone recrystallization. The former is important from a corrosion aspect, as the presence of TCP phases indicates chemical segregation and local depletion of $\mathrm{Cr}$ and $\mathrm{Mo}$ and hence a potential decrease of corrosion performance. Based on the results, it was observed that solution annealing at higher temperatures $\left(1200^{\circ} \mathrm{C}\right.$ and $\left.1300^{\circ} \mathrm{C}\right)$ or longer durations at lower temperatures $\left(1075^{\circ} \mathrm{C}\right.$ and $\left.1121^{\circ} \mathrm{C}\right)$ are required to dissolve TCP phases. Since it would be unrealistic to hold the waste container for multiple days at these elevated temperatures during fabrication, solution annealing at either $1075^{\circ} \mathrm{C}$ or $1121^{\circ} \mathrm{C}$ does not provide a viable solution. This leaves solution annealing for 20 minutes at either $1200^{\circ} \mathrm{C}$ or $1300^{\circ} \mathrm{C}$. Considering the coarsening observed in the $1300^{\circ} \mathrm{C}$ specimen, and the relatively homogeneous nature of the grain structure in the $1200^{\circ} \mathrm{C}$ specimen, the choice of solution annealing at $1200^{\circ} \mathrm{C}$ for 20 minutes appears to be the most appropriate treatment to perform from a microstructural point of view.

Optical microscopy examination indicates less localized corrosion degradation with increasing annealing temperatures in both the $1 \mathrm{M} \mathrm{NaCl}$ and $6 \mathrm{~m} \mathrm{NaCl}+0.9 \mathrm{~m} \mathrm{KNO}_{3}$. However, the residual surface oxide from the annealing process may have obscured the quantification of the localized corrosion susceptibility from the CPP curves. 


\section{Mock up Waste Package Studies}

\subsection{Methods}

Two "hockey puck" specimens were examined in this study. One specimen was obtained from the longitudinal seam weld as close to the trunnion as possible, and the second from the longitudinal seam weld underneath the trunnion. The sections examined are illustrated schematically in Figure 4.1.1 (section A represents the longitudinal seam weld specimen, and section $B$ represents the trunnion weld specimen).
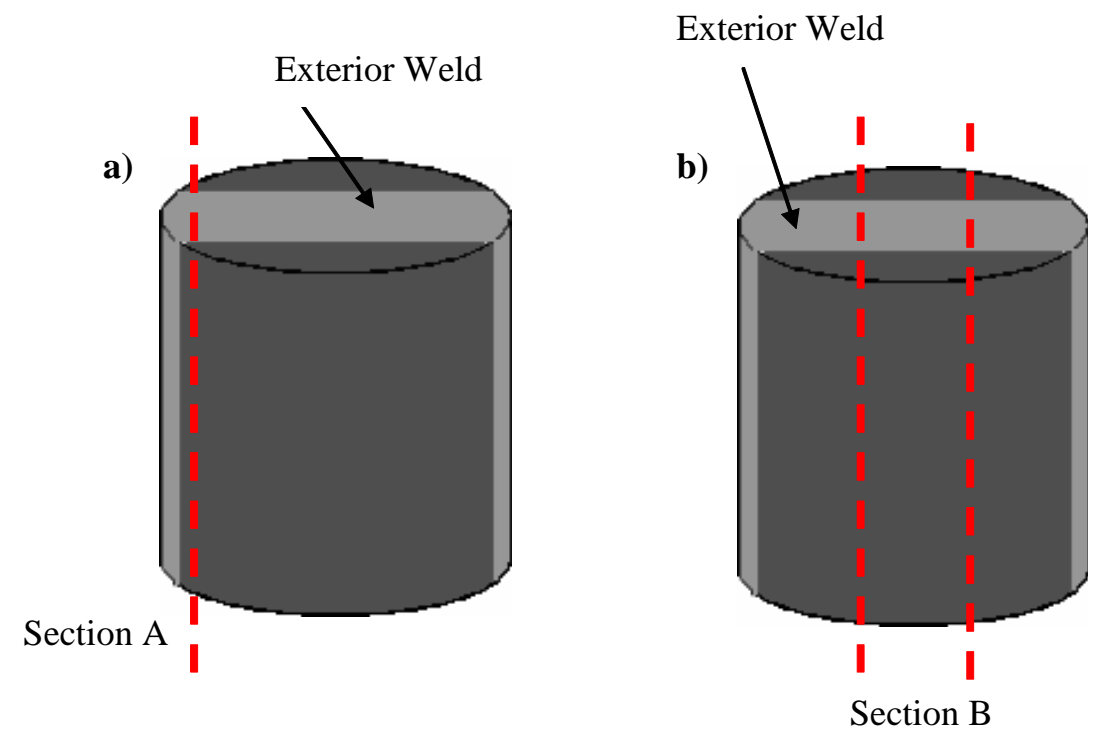

Figure 4.1.1. Schematic illustrating hockey puck sections observed for a) the hockey puck obtained from the longitudinal seam weld region near the trunnion and $b$ ) the hockey puck obtained from the longitudinal seam weld beneath the trunnion.

\subsubsection{TCP Phase Quantification}

Backscatter electron imaging was used as described in Section 1.2.1 to document the presence of TCP phases in both specimens. To obtain an estimate of total volume fraction of TCP phases in each specimen, the top of the weld regions across the entire width ( $-30 \mathrm{~mm}$ for the trunnion weld and $21 \mathrm{~mm}$ for the seam weld by a $4 \mathrm{~mm}$ depth) of both specimens were imaged and analyzed. A total of 223 images were captured: 144 images for the longitudinal seam weld, 79 images for the trunnion weld, respectively.

\subsubsection{Phase Identification}

Since the three possible TCP phases are crystallographically different (tetragonal for $\sigma$, rhombohedral for $\mu$, and orthorhombic for P), EBSD patterns from each of the phases would be unique to that phase. The technique described in Section 1.2.2 was utilized in an automated scan across the area near the top of the weld on the trunnion specimen where regions of secondary phases were observed that were not seen in the longitudinal seam weld specimen. Further characterization was limited to only the trunnion specimen since no similar regions of secondary phases were observed. Automated scanning was possible in this region since the particle sizes were large $(\sim 2-5 \mu \mathrm{m})$. 


\subsubsection{TCP Phase Chemical Composition}

Wavelength-Dispersive Spectroscopy (WDS), described in Section 1.2.3, was used to determine the compositional chemical variations of the TCP phases and adjacent matrix regions observed near the top of the trunnion longitudinal seam weld specimen.

\subsection{Results and Discussion}

\subsubsection{TCP Phase Stability}

Using the preliminary automated method of analysis it was observed that although both the trunnion and seam welds have an extremely small volume fraction of precipitates, the trunnion weld had about twice the amount of secondary phase content than the longitudinal seam weld (both were less than $0.1 \%$ ). Both specimens contained weld porosity (which was not measured) formed by gas entrapment during solidification from the welding process.

Table 4.2.1.1. TCP volume fraction for the seam and trunnion welds (Source: DTN LL050304412251.137)

\begin{tabular}{|c|c|}
\hline Specimen Description & TCP Vol. Fraction (\%) \\
\hline Trunnion Weld & $<0.05$ \\
\hline Seam Weld & $<0.05$ \\
\hline
\end{tabular}

Comparison to the data presented in Section 3.2.1 for the specimen solution annealed at $1121^{\circ} \mathrm{C}$ for 20 minutes shows that the dissolution of TCP phases in the weld region of the mockup package was more extensive, with almost two orders of magnitude less TCP phase volume fraction.

Although the overall TCP volume fraction was less than $0.05 \%$ in both specimens, for the trunnion weld, the majority of the precipitate volume fraction was observed at the exterior of the weld surface as shown in Figure 4.2.1.1. The region shown in Figure 4.2.1.1 is of interest as it is representative of the surface that could be most susceptible to corrosion, and therefore the identification of the type of phase(s) present in this region is important.

While the reason for the presence of this localized secondary phase is not definitively known, it is likely in part due to the presence of the trunnion, which prevented the surfaces beneath to cool at the same rate as the "exposed" waste container surfaces during solution annealing. Another reason for the location of these phases is the presence of a free surface, which can make phase transformations occur easier as lattice mismatches between the phases and the matrix do not yield the same amount of stress. 


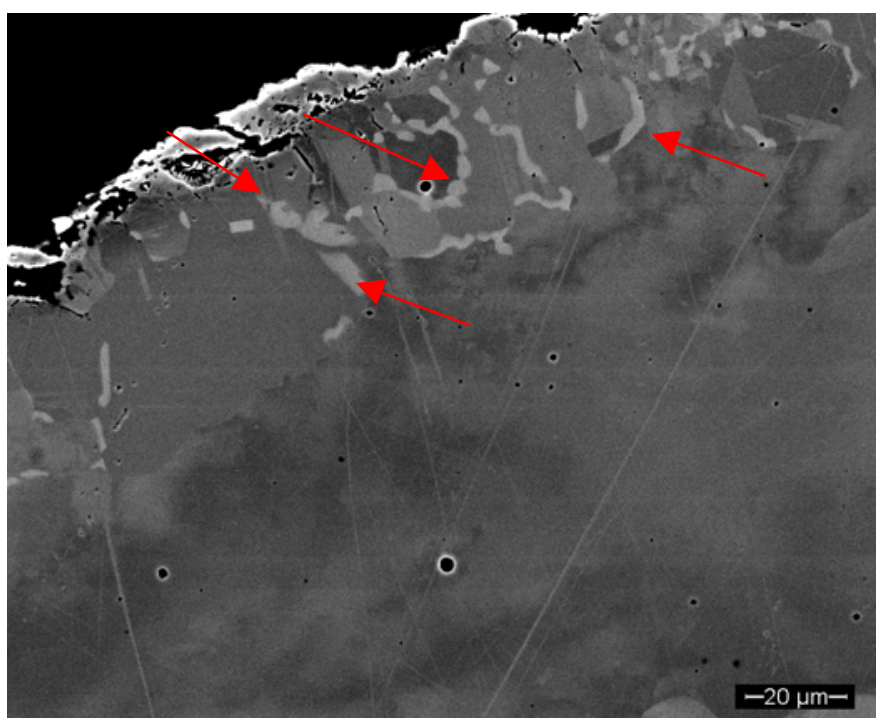

Figure 4.2.1.1. Micrograph of the top cross-sectional area of the trunnion longitudinal seam weld specimen, illustrating the presence of a secondary phase at the weld surface (indicated by red arrows). (Source: DTN LL050304312251.136)

\subsubsection{TCP Phase Identification}

The region near the surface of the trunnion weld (shown in Figure 4.2.1.1) was scanned using EBSD to identify the phase(s). The results shown in Figure 4.2.2.1 show that virtually all of the secondary phases observed are $\sigma$ phase. While it is known that $\sigma$ can be stable at high temperatures [8], none was observed in the solution annealing study for specimens annealed for durations $<24$ hours. Therefore another driving force for this transformation must exist. A possible driving force may be excessive $\mathrm{Cr}$ or Mo segregation, perhaps due to slow cooling of the weld pool during fabrication or solution annealing (since $\sigma$ is more stable at higher $\mathrm{Cr}$ and Mo content).

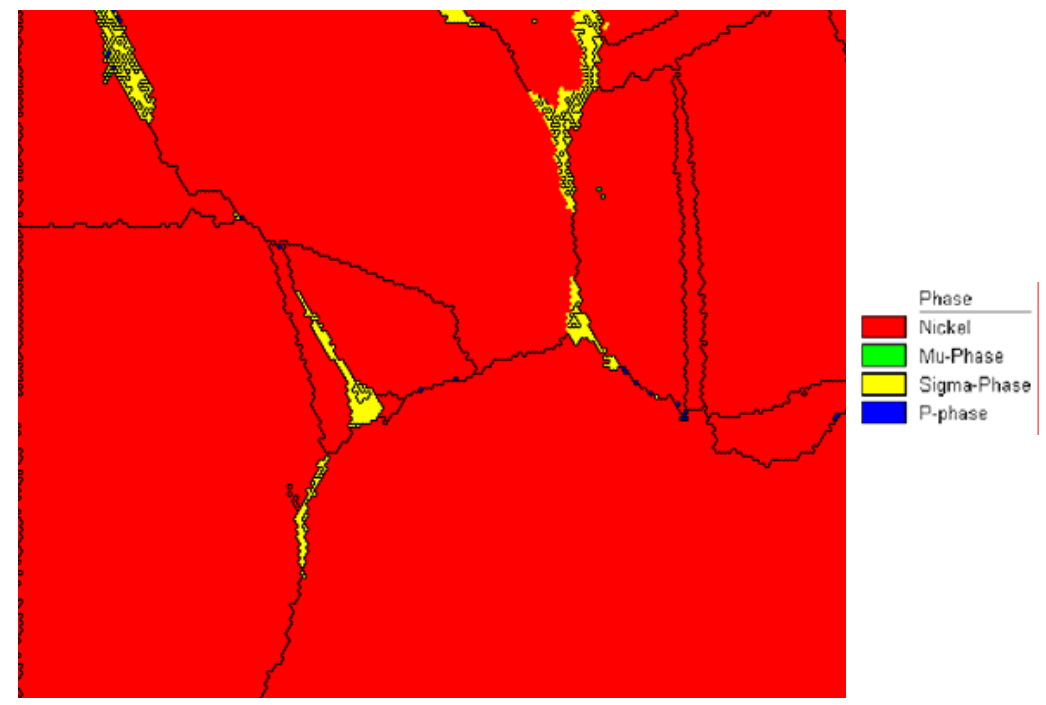

Figure 4.2.2.1. Phase ID map of the near-surface region of the hockey puck trunnion longitudinal seam weld specimen. (Source: DTN LL050304212251.135) 


\subsubsection{TCP Phase Chemical Composition}

Figure 4.2.3.1 shows a micrograph indicating the areas of the hockey puck trunnion longitudinal seam weld specimen where Wavelength-Dispersive Spectroscopy (WDS) was used to determine the variation in chemical composition. Locations $1-3$ are measurements made directly on the TCP phase determined by EBSD to be $\sigma$ and locations $4-6$ are measurements directly adjacent to the TCP phases. Locations 7-9 are within "lighter" areas (indicating compositional differences compared to the matrix) and locations $10-12$ are of the matrix far away from any observed phases.

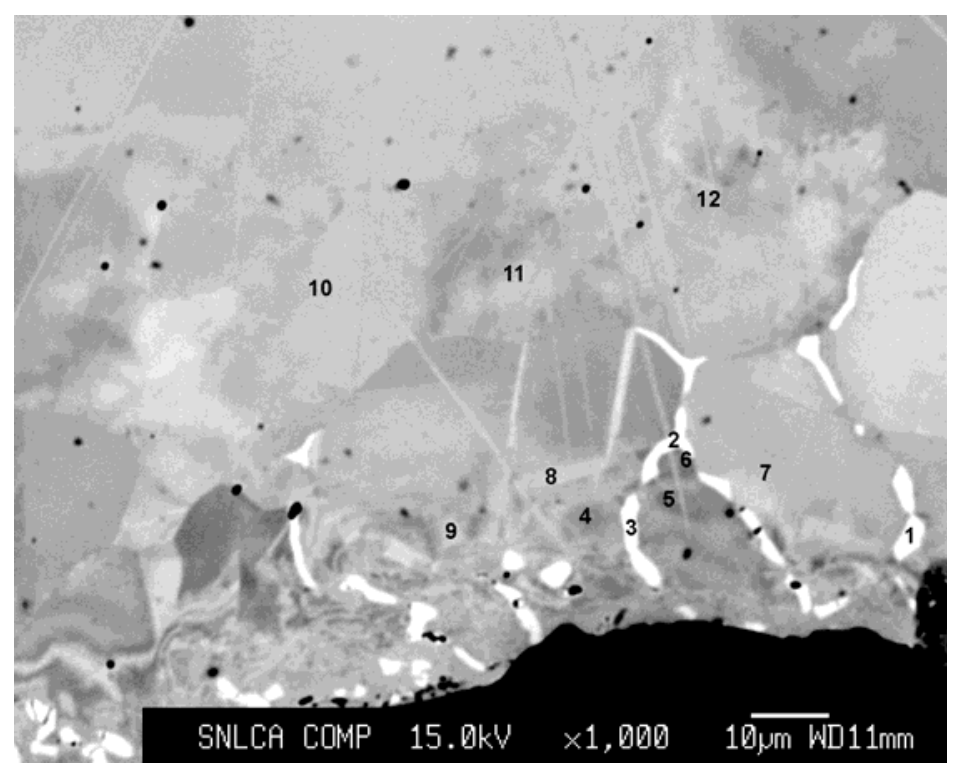

Figure 4.2.3.1. Micrograph showing numbered regions of the trunnion longitudinal seam weld specimen analyzed for chemical segregation using WDS. (Source: DTN LL050901612251.041)

The elemental weight percent values measured at each of the numbered points are listed in Table 4.2.3.1. The results obtained from the $\sigma$ phases (locations $1-3$ ) show a very high $\mathrm{Cr}$ and Mo content, where the regions adjacent to the phases possess $\mathrm{Cr}$ and Mo weight percent approximately $2 \%$ lower than that measured in the matrix. The excess $\mathrm{Cr}$ and $\mathrm{Mo}$ in the phases combined with the $\mathrm{Cr}$ and $\mathrm{Mo}$ depleted zone surrounding the phases indicate that a large amount of segregation is the reason for the formation of the $\sigma$ phases observed.

If we consider the elemental weight percent values published in [8] for the three TCP phases $(\sigma, \mu$, and P) seen in the weld fusion zone (Table 4.2.3.2), it is clear that $\sigma$ contains the most $\mathrm{Cr}$, indicating that it is the most stable of the three with high $\mathrm{Cr}$ content. This is also verified in examination of the phase diagrams in [8]. The higher $\mathrm{Cr}$ content not only played a part in the formation of the $\sigma$ phase, but it also may have prevented it from transforming into $\mu$ or $\mathrm{P}$ during cooling.

Note: $\quad$ The weight percentages shown in Table 4.2.3.1 do not total 100\% because they were not normalized. 
Table 4.2.3.1. WDS results in weight percent (wt. \%) for chromium, molybdenum, nickel, and tungsten as measured in the hockey puck trunnion longitudinal seam weld specimen (Source: DTN LL050901612251.041)

\begin{tabular}{|c|c|c|c|c|c|}
\hline \multirow{2}{*}{ Location } & \multicolumn{5}{|c|}{ Elemental Weight Percent (\%) } \\
\cline { 2 - 6 } & $\mathbf{C r}$ & $\mathbf{M o}$ & $\mathbf{N i}$ & $\mathbf{W}$ & Total \\
\hline $\mathbf{1}$ & 29.2 & 29.7 & 33.3 & 4.7 & 96.9 \\
\hline $\mathbf{2}$ & 27.9 & 28.4 & 34.5 & 4.5 & 95.3 \\
\hline $\mathbf{3}$ & 28.2 & 29.0 & 34.5 & 4.6 & 96.3 \\
\hline $\mathbf{4}$ & 20.9 & 13.4 & 60.4 & 2.8 & 97.6 \\
\hline $\mathbf{5}$ & 20.2 & 12.6 & 62.0 & 2.8 & 97.5 \\
\hline $\mathbf{6}$ & 20.0 & 12.1 & 62.9 & 2.4 & 97.4 \\
\hline $\mathbf{7}$ & 21.3 & 13.5 & 60.7 & 2.7 & 98.2 \\
\hline $\mathbf{8}$ & 21.4 & 14.0 & 60.0 & 3.0 & 98.4 \\
\hline $\mathbf{9}$ & 20.9 & 13.9 & 60.6 & 3.0 & 98.5 \\
\hline $\mathbf{1 0}$ & 21.6 & 14.4 & 60.3 & 3.3 & 99.6 \\
\hline $\mathbf{1 1}$ & 21.8 & 14.1 & 60.3 & 2.9 & 99.1 \\
\hline $\mathbf{1 2}$ & 21.4 & 14.1 & 59.8 & 2.9 & 98.2 \\
\hline
\end{tabular}

Table 4.2.3.2. Chemical composition (wt. \%) of TCP phases. (Source: [8])

\begin{tabular}{|c|c|c|c|c|}
\hline Phase & Cr & Mo & Ni & W \\
\hline$\sigma$ & 23 & 35 & 34 & 4.2 \\
\hline $\mathrm{P}$ & 21 & 37 & 33 & 5 \\
\hline$\mu$ & 20 & 39 & 33 & 6.3 \\
\hline
\end{tabular}

Figure 4.2.3.2 shows a graphical representation of a WDS trace collected across the region containing the $\sigma$ phase. The trace indicates that as chromium, molybdenum, and tungsten increase, there is a depletion of nickel in the matrix at the dendrite boundaries due to the formation of $\sigma$. 


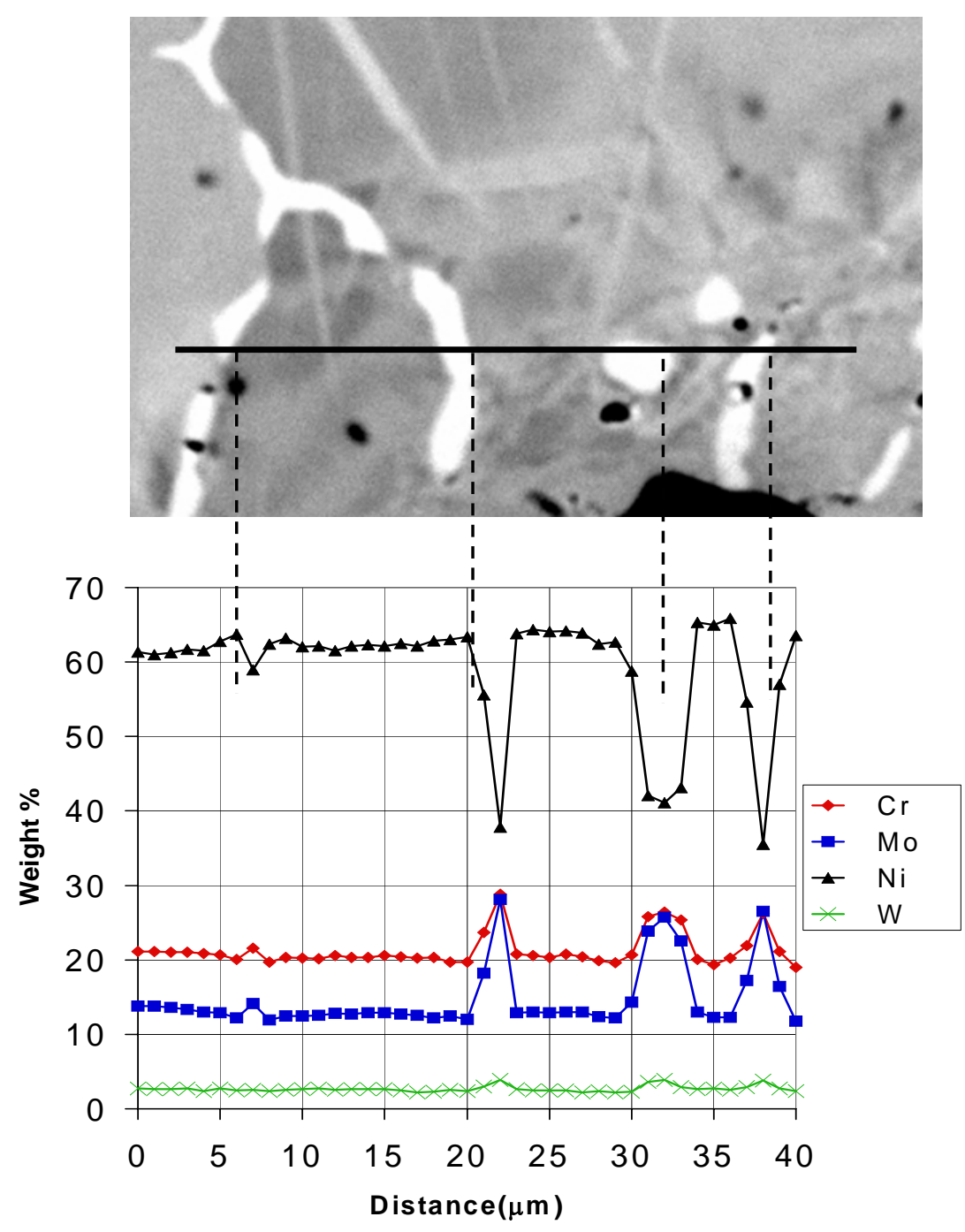

Figure 4.2.3.2. WDS traces with corresponding micrograph showing compositional variations across and adjacent to TCP phases. (Source: DTN LL050901612251.041)

\subsection{Summary}

Solution annealing of the mockup waste container appears to decrease the total concentrations of TCP phases in the fusion zone of the weld. The weld region beneath the trunnion showed an increase in the amount of secondary phases at the top of the weld, in contrast with the longitudinal seam weld region not covered by the trunnion.

This secondary phase was determined to be $\sigma$ which was rich in $\mathrm{Cr}$. The source of this phase is increased segregation of $\mathrm{Cr}$ to the interdendritic region either during the welding of the seam or as a result of the heat input from welding the trunnion to the container. The high $\mathrm{Cr}$ content may have allowed the $\sigma$ phase to remain stable during the cooling of the container after quenching. 


\section{Effect of Stress Mitigation Processes on Secondary Phase Precipitation During Thermal Aging}

\subsection{Methods}

The effect of stress mitigation on TCP phases was investigated by LLNL on eight specimens that were prepared for SEM analyses. One specimen from each plate was characterized in the as-fabricated condition to use as a comparison for the specimens that would be aged. The specimens aged at $700^{\circ} \mathrm{C}$ were aimed at determining the precipitation rate of TCP phases. The specimens aged at $550^{\circ} \mathrm{C}$ were aimed at precipitating the ordered phase (since LRO occurs below $\left.600^{\circ} \mathrm{C}\right)$.

Two of the specimens were as-fabricated, three were burnished and three were laser peened. One specimen from each set of three was aged at $700^{\circ} \mathrm{C}$ for 50 hours, and another set of three specimens were aged at $700^{\circ} \mathrm{C}$ for 500 hours. These eight specimens were studied for TCP phase content and type.

Characterization of the effect of stress mitigation on LRO was performed by Sandia National Laboratories (SNL) for three weld specimens aged at $550^{\circ} \mathrm{C}$ for 1000 hours and one asfabricated (non-aged/treated) weld. Of the aged specimens, one was as-welded (untreated), the second a burnished weld, and the third a laser shock peened weld. These specimens were prepared for and studied using a Transmission Electron Microscope (TEM).

\subsubsection{TCP Phase Quantification}

Backscatter electron imaging was used to identify the presence of TCP phases in six of the specimens aged at $700^{\circ} \mathrm{C}$ and one each of the as-welded specimens from the burnished and peened plates. The method used is outlined in Section 1.2.1. For each specimen, approximately 40 micrographs were captured at 1500X.

\subsubsection{TCP Phase Identification}

The method described in Section 1.2.2 was employed to identify the TCP phases. Due to the small size of the TCP phases present in the fusion zone of the weld, automated EBSD scans could not be performed. A manual method of acquiring the phase identifications was developed where multiple areas of a specimen were randomly imaged at a high magnification $(12,000 \mathrm{X})$ and diffraction patterns would be collected from all the phases present in the field of view of any given image. The phases that yielded poor or no diffraction would be considered "unidentified".

This manual process was carried out on the six aged specimens, with up to 30 diffraction patterns collected and identified (indexed) per specimen. Once all the TCP phase information was collected, a relative volume fraction consisting of four components $(\sigma, \mu, P$, and unidentified) was calculated based on the relative area fractions of the identified and unidentified TCP phases imaged.

\subsubsection{LRO Phase Characterization}

The determination of the ordered phase content in the specimens aged at $550^{\circ} \mathrm{C}$ was conducted using TEM analyses. Multiple regions of each of the three specimens were imaged in dark-field mode to elucidate the presence of the ordered phase regions, with 6 variants imaged for each area in order to allow for statistical accuracy in calculating the LRO volume fraction. For comparison, a specimen in the as-welded condition was also prepared and imaged. 


\subsection{Results and Discussion}

\subsubsection{Phase Stability}

It was observed that the microstructure of the specimens aged at $700^{\circ} \mathrm{C}$ for 50 hours were very similar to the as-welded (non-aged) specimens. This is reflected in the volume fractions shown in Table 5.2.1.1. However, after aging at $700^{\circ} \mathrm{C}$ for 500 hours, the TCP phase volume fraction grew substantially.

Table 5.2.1.1. Effect of Stress Mitigation and Aging at $700^{\circ} \mathrm{C}$ on TCP Phase Volume Fraction (Source: DTN LL050303412251.026)

\begin{tabular}{|c|c|c|c|c|c|c|c|c|}
\hline Aging Times & \multicolumn{2}{|c|}{$\mathbf{0}$ Hours at $700^{\circ} \mathrm{C}$} & \multicolumn{3}{|c|}{50 Hours at $700^{\circ} \mathrm{C}$} & \multicolumn{3}{c|}{500 Hours at $700^{\circ} \mathrm{C}$} \\
\hline $\begin{array}{c}\text { Mitigation } \\
\text { Condition }\end{array}$ & Burnished & Peened & Untreated & Burnished & Peened & Untreated & Burnished & Peened \\
\hline $\begin{array}{c}\text { Volume } \\
\text { Fraction (\%) }\end{array}$ & 0.09 & 0.11 & 0.08 & 0.14 & 0.13 & 1.89 & 6.53 & 1.89 \\
\hline $\begin{array}{c}\text { Standard } \\
\text { Deviation }\end{array}$ & 0.06 & 0.06 & 0.07 & 0.08 & 0.09 & 1.25 & 2.69 & 0.97 \\
\hline
\end{tabular}

Figure 5.2.1.1 shows a comparison of the untreated, burnished, and peened specimens. All three specimens contained small particles of precipitates that decorate the interdendritic region between the secondary dendrites.
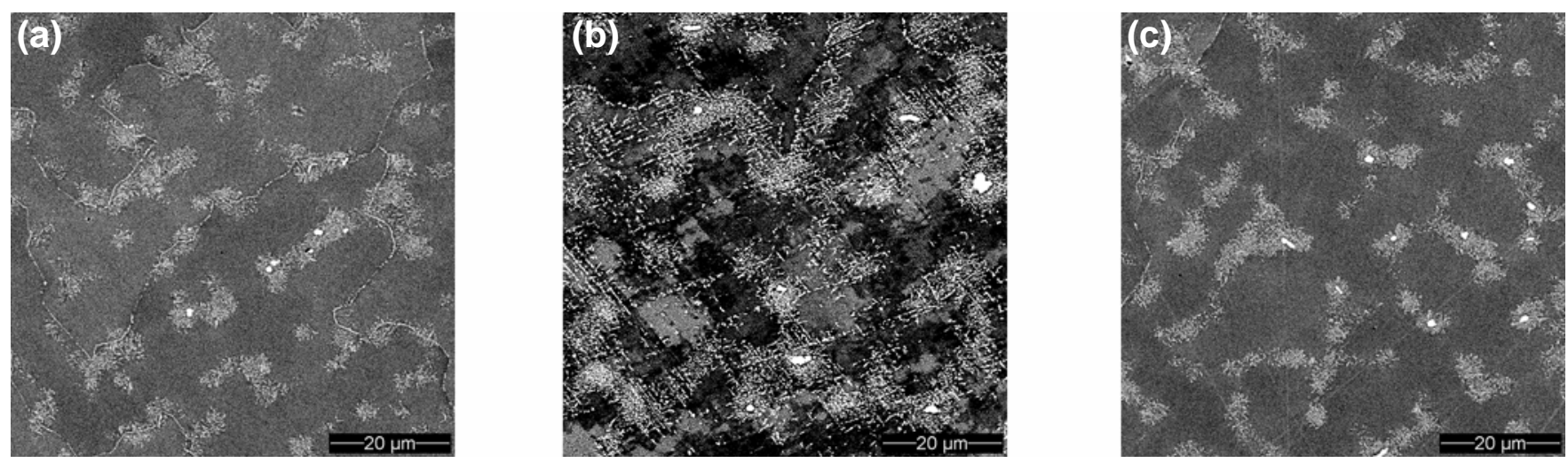

Figure 5.2.1.1. Cross-sectional backscattered electron micrographs of (a) untreated, (b) low plasticity burnished, and (c) laser shock peened Alloy 22 welds aged at $700^{\circ} \mathrm{C}$ for 500 hours. (Source: DTN LL050303312251.025)

The burnished specimen shows additional TCP phase formation around the dendrite boundaries and on straight lines within the dendrites, perhaps on crystallographic slip plane traces. These features can be clearly seen in Figure 5.2.1.2. It should be noted that these features were more prevalent in the top $1 \mathrm{~mm}$ of the weld where deformation from the burnishing process was greatest. 


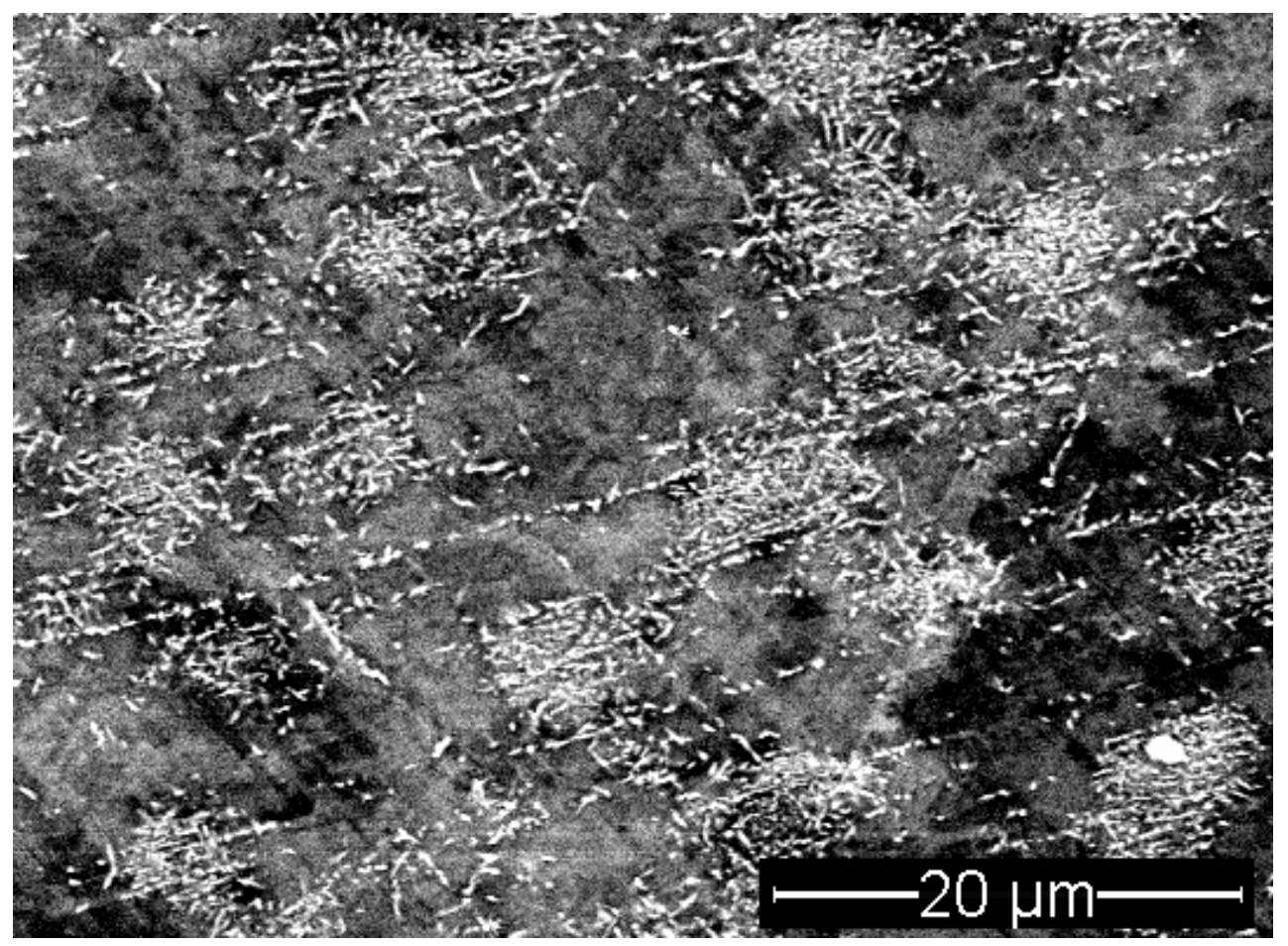

Figure 5.2.1.2. High magnification image of the low plasticity burnished Alloy 22 weld aged for 500 hours at $700^{\circ} \mathrm{C}$. Micrograph was obtained within $1 \mathrm{~mm}$ of the top of the weld. (Source: DTN LL050303312251.025)

\subsubsection{Phase Identities}

Collected diffraction patterns were used to identify the phases in the six specimens aged at $700^{\circ} \mathrm{C}$ for 50 and 500 hours. Of the possible phases $(\sigma, \mu$, and $\mathrm{P})$, diffraction patterns of only $\mathrm{P}$ and $\mu$ were observed. Examples of these diffraction patterns are shown in Figure 5.2.2.1.
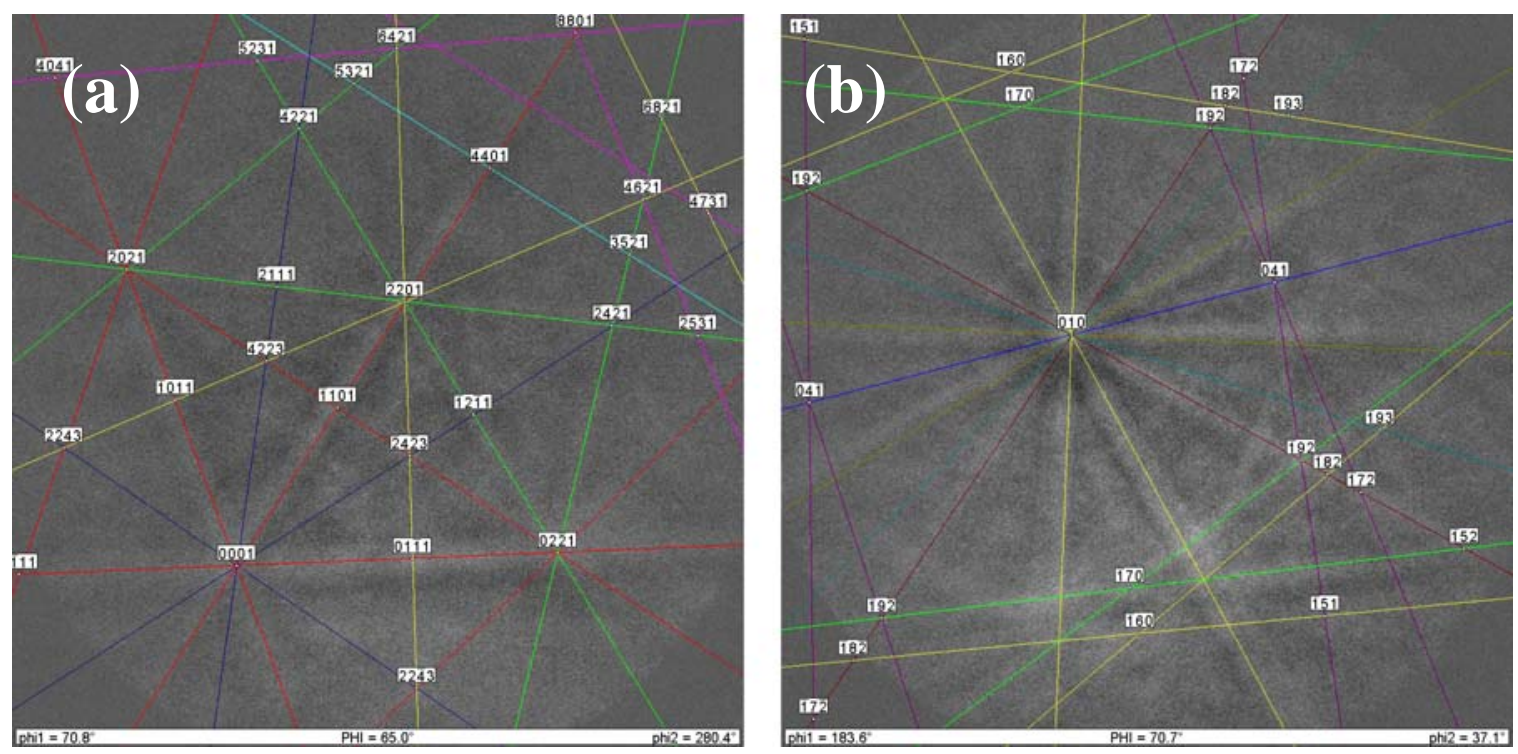

Figure 5.2.2.1. Electron Backscatter Diffraction Patterns from (a) a $\mu$-phase precipitate, and (b) a P-phase precipitate. (Source: DTN LL050303112251.023) 
Results of the calculation of the relative volume fractions for all six specimens are shown in Table 5.2.2.1. Of the TCP phases identified the dominant phase is $\mathrm{P}$ and the specimens aged at $700^{\circ} \mathrm{C}$ for 500 hours have a higher degree of unidentifiable TCP phases.

Table 5.2.2.1. Effect of Stress Mitigation and Aging at $700^{\circ} \mathrm{C}$ on observed TCP phase types (Source: DTN LL050303212251.024)

\begin{tabular}{|c|c|c|c|c|c|}
\hline \multirow{2}{*}{$\begin{array}{l}\text { Stress Mitigation } \\
\text { Treatment }\end{array}$} & \multirow{2}{*}{$\begin{array}{c}\text { Aging Time @ } \\
700^{\circ} \mathrm{C} \text { (hrs.) }\end{array}$} & \multicolumn{4}{|c|}{ TCP Phase Volume Fraction (\%) } \\
\hline & & $\mathbf{P}$ & $\mu$ & $\bar{\sigma}$ & Unidentified \\
\hline None & 50 & 49.3 & 22.8 & 0.0 & 27.9 \\
\hline None & 500 & 37.7 & 27.0 & 0.0 & 35.3 \\
\hline Burnished & 50 & 51.5 & 17.1 & 0.0 & 31.3 \\
\hline Burnished & 500 & 47.8 & 1.7 & 0.0 & 50.5 \\
\hline Peened & 50 & 59.5 & 9.9 & 0.0 & 30.6 \\
\hline Peened & 500 & 51.4 & 8.5 & 0.0 & 40.0 \\
\hline
\end{tabular}

Characterization of the TCP phase types present showed that the majority of those identifiable are $\mathrm{P}$ phase, with the remainder being $\mu$ phase. The fact that no sigma phases were observed does not fully preclude them from existing at these temperatures but indicates that if they are present they are not sufficiently stable to coarsen to an extent that would render them identifiable. The observation that $P$ phase appears to be stable supports the predictions of the Aging and Phase Stability (APS) Model at this temperature as stated in Chapter 6 of ANL-EBS-MD-000002.

\subsubsection{LRO Characterization}

Characterization of the as-welded specimen showed no signs of LRO phases present. This is clearly seen in Figure 5.2.3.1 where the presence of dislocations can be seen and the selected area electron diffraction (SAED) pattern shows the absence of any superlattice reflections (indicating no ordered phase).
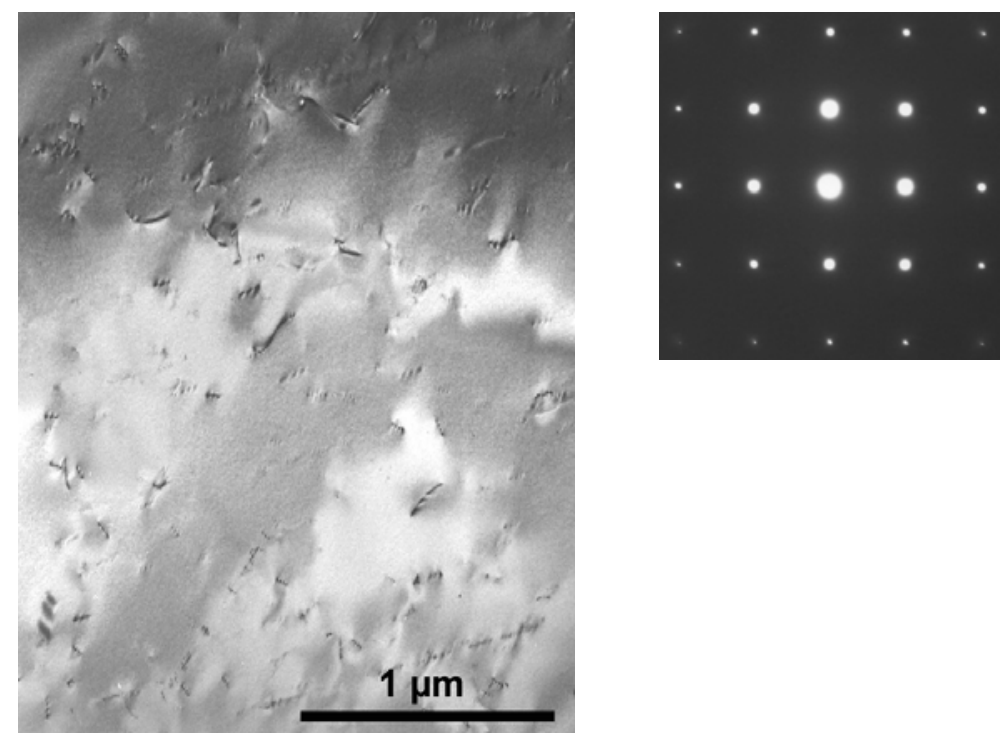

Figure 5.2.3.1. As-welded specimen (untreated). Bright-field image of matrix $(\sim 1.3 \mathrm{~mm}$ from the top of the weld) showing dislocations (left) and [001] SAED pattern showing no superlattice reflections indicating no LRO precipitates (right). (Source: DTN LL050901312251.038) 
By contrast, the as-welded specimen aged at $550^{\circ} \mathrm{C}$ for 1000 hours contains both dislocations and the ordered phase (Figure 5.2.3.2). The ordered phase precipitates were verified by the presence of the superlattice reflection pattern in the SAED and is also shown in the dark field image. The superlattice reflections are uniform in intensity indicating that there are random orientations. Note: The TEM specimens were taken $1.45 \mathrm{~mm}$ from the top of the weld.
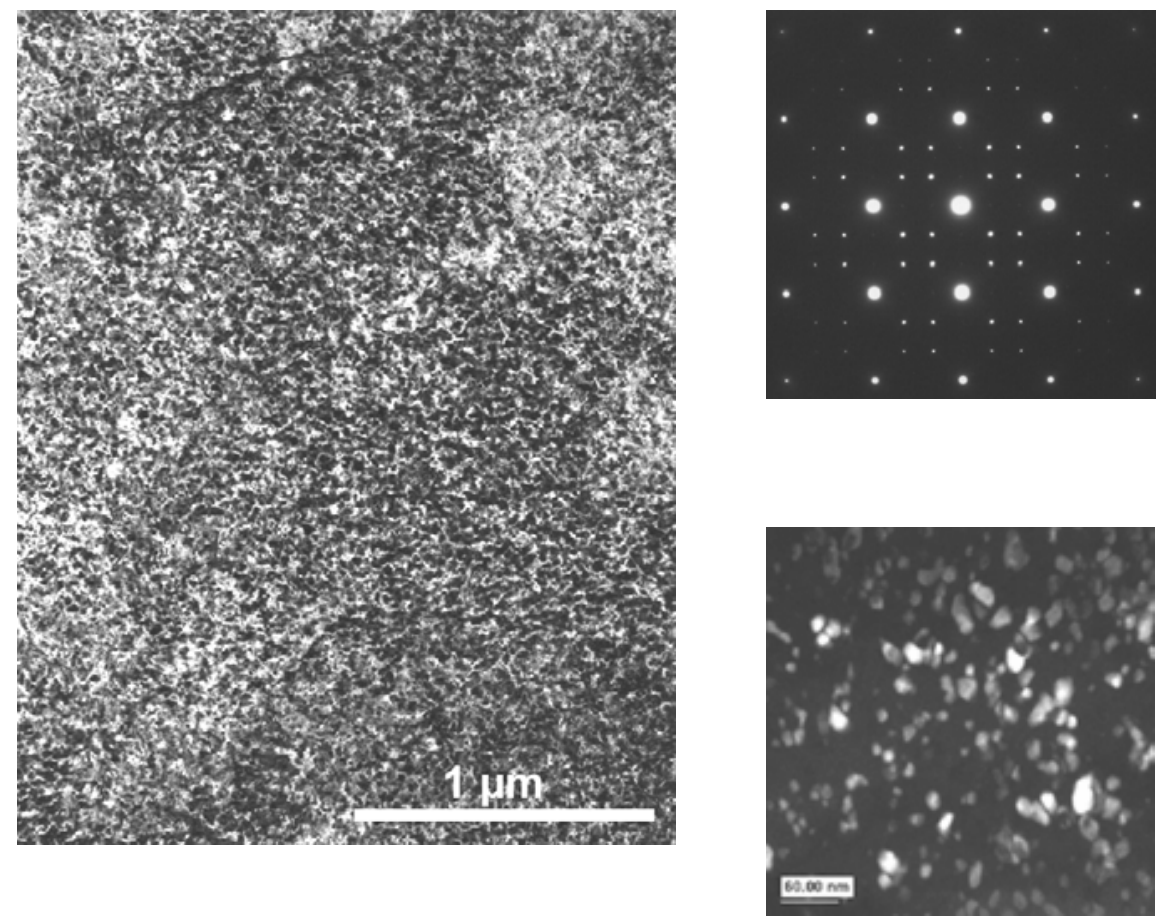

Figure 5.2.3.2. As-welded specimen aged at $550^{\circ} \mathrm{C}$ for 1000 hours. Bright field image of matrix shows the fine complex features of precipitates/dislocations (left). [001] SAED pattern with LRO superlattice reflections (upper right). Dark field image of LRO phase, one variant, the LRO $\sim 10-30 \mathrm{~nm}$ (lower right). (Source: DTN LL050901312251.038)

In Figure 5.2.3.3 the images acquired from the laser peened specimen aged at $550^{\circ} \mathrm{C}$ for 1,000 hours are shown. The SAED pattern shows two "brighter" diagonal spots in the superlattice reflections, indicating possible preferred orientation compared to the SAED pattern in Figure 5.2.3.2 for the as-welded aged specimen. Similar diagonal bright spots can be seen in the SAED of the burnished specimen aged at $550^{\circ} \mathrm{C}$ for 1,000 hours in Figure 5.2.3.4. This specimen also contains a non-uniform fine microstructure as well as a large number of twins (most likely deformation twins). 

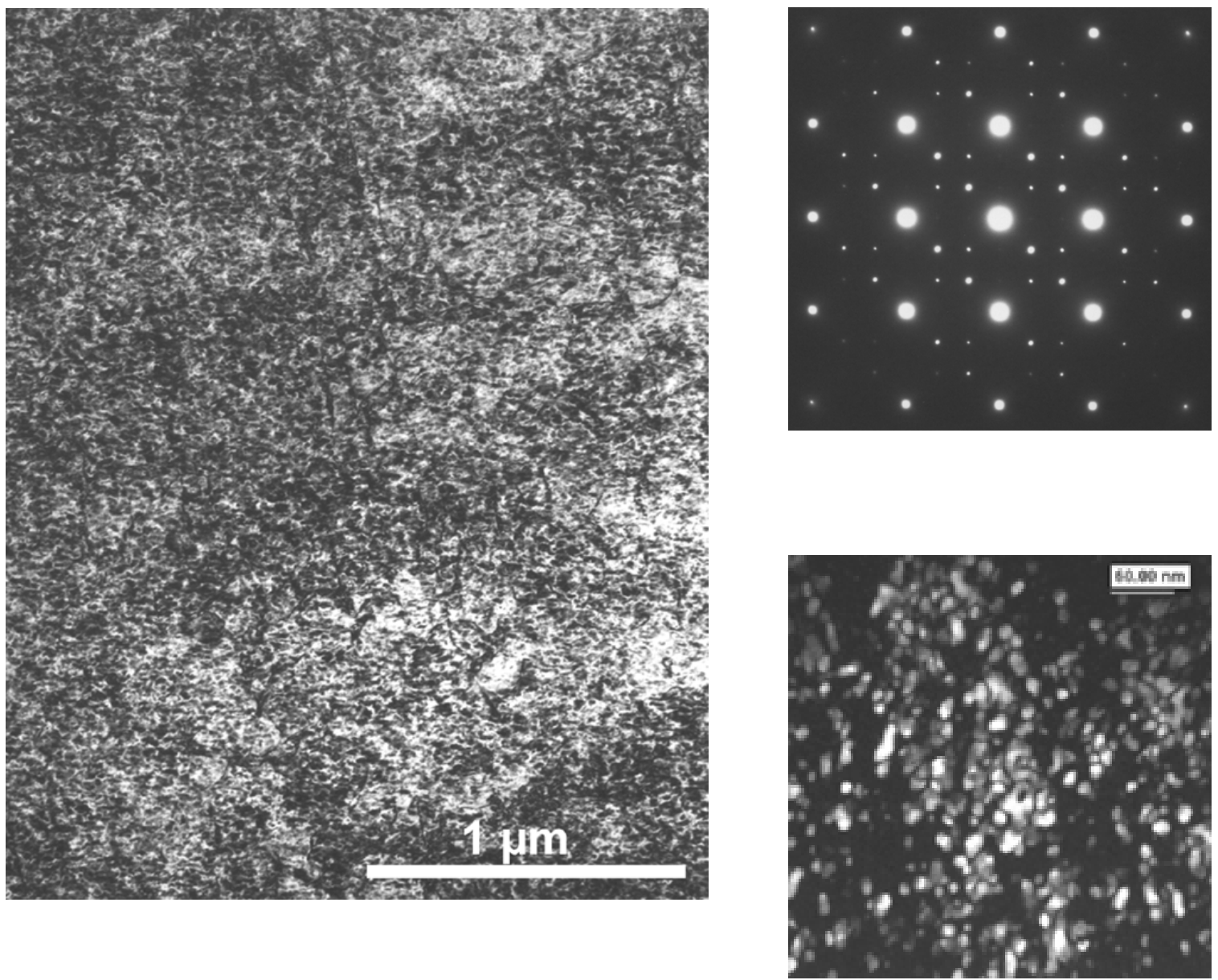

Figure 5.2.3.3. Laser peened specimen aged at $550^{\circ} \mathrm{C}$ for 1000 hours. Bright field image (left), [001] SAED pattern showing LRO superlattice reflections (upper right). Dark field image of LRO phase, one variant (lower right). (Source: DTN LL050901312251.038) 

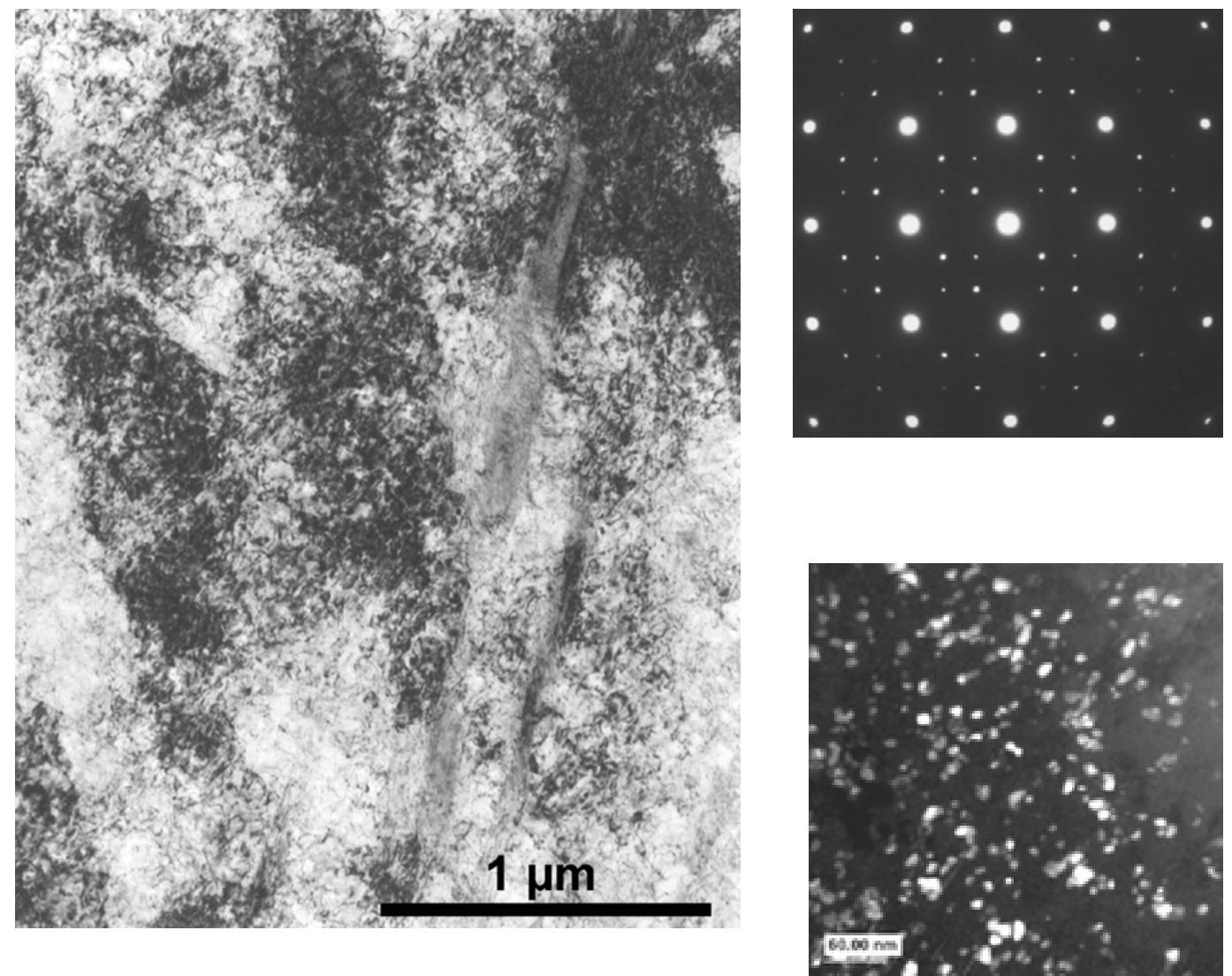

Figure 5.2.3.4. Burnished specimen aged at $550^{\circ} \mathrm{C}$ for 1000 hours. Bright field image (left). [001] SAED pattern showing LRO superlattice reflections (upper right). Dark field image of LRO phase, one variant (lower right). (Source: DTN LL050901312251.038)

\subsection{Summary}

Alloy 22 weld specimens subject to the stress mitigation techniques of low plasticity burnishing and laser shock peening were studied by LLNL for TCP phase stability by aging at $700^{\circ} \mathrm{C}$ for 50 and 500 hours. In comparison to non-aged specimens, aging for 50 hours provided little change in the observable TCP phase content, with total volume fraction values near $0.1 \%$. Aging for 500 hours increased the amount of TCP phases, which primarily precipitated between the secondary dendrites of the weld fusion zone. A noticeable difference was observed for the burnished specimen aged at $700^{\circ} \mathrm{C}$ for 500 hours, increased precipitation resulted in a total volume fraction approximately three times that of the untreated or laser peened specimens aged for the same duration.

Alloy 22 weld specimens subjected to the same stress mitigation techniques were characterized by SNL for the presence of LRO by aging them at $550^{\circ} \mathrm{C}$ for 1000 hours. Characterization of the as-fabricated welded specimen showed no signs of LRO. All the aged samples contained a fine microstructure which consisted of a mix of dislocations and the ordered phase. The burnished specimen however, contained a high density of twins.

Due to the difficult nature of quantification of objects in TEM micrographs, values for the volume fraction of LRO in the aged specimens is still being investigated. However, based on the TEM micrographs obtained from each of the aged specimens, it is apparent that they all contain a high fraction of the ordered phase. 


\section{Evaluation of Weld Stability in Prototypical Thick Welds}

\subsection{Methods}

Analyses of six of the seventeen Alloy 22 thick ( 1.25") weld specimens that were aged from 200 to $750^{\circ} \mathrm{C}$ (see TWP-WIS-MD-000011) were conducted. The specimens analyzed to date are those aged at $650^{\circ} \mathrm{C}$ for 20 and 100 hours and the remaining four at $700^{\circ} \mathrm{C}$ and $750^{\circ} \mathrm{C}$ for 10 and 100 hours. Characterization requires a polished specimen surface and all specimens evaluated were metallurgically prepared by successive grinding to 1200 grit using silicon carbide paper; followed by successive polishing to $0.02 \mu \mathrm{m}$ with colloidal silica. Analyses of the remaining aged specimens are currently in progress.

Backscatter electron imaging was used to identify the presence of TCP phases in all six specimens. The method used is described in Section 1.2.1. For each specimen, between 50 and 60 micrographs were captured at 1500X and analyzed.

\subsection{Results and Discussion}

Analysis of the micrographs, as tabulated in Table 6.2 .1 shows that the kinetics at $650^{\circ} \mathrm{C}$ for precipitation are slow, with virtually no difference in the TCP phase volume fraction between 20 and 100 hours of aging. A marginal increase in TCP phase volume fraction can be seen between the specimens aged at $700^{\circ} \mathrm{C}$, the specimen aged for 100 hours contained approximately 5 times the volume fraction as the specimen aged for 10 hours. A more significant increase is seen at $750^{\circ} \mathrm{C}$ however, with a 20 -fold increase in the TCP phase volume fraction between the 10 and 100 hour specimens.

Table 6.2.1. Effect of Aging Time and Temperature on TCP Phase Content of Alloy 22 Thick Welds (Source: DTN LL050304912251.142)

\begin{tabular}{|l|c|c|}
\hline Description & Volume Fraction (\%) & Standard Deviation \\
\hline Alloy 22 Thick Weld Aged at $650^{\circ} \mathrm{C} / 20$ hours & 0.16 & 0.12 \\
\hline Alloy 22 Thick Weld Aged at $650^{\circ} \mathrm{C} / 100$ hours & 0.10 & 0.11 \\
\hline Alloy 22 Thick Weld Aged at $700^{\circ} \mathrm{C} / 10$ hours & 0.14 & 0.12 \\
\hline Alloy 22 Thick Weld Aged at $700^{\circ} \mathrm{C} / 100$ hours & 0.78 & 0.83 \\
\hline Alloy 22 Thick Weld Aged at $750^{\circ} \mathrm{C} / 10$ hours & 0.21 & 0.18 \\
\hline Alloy 22 Thick Weld Aged at $750^{\circ} \mathrm{C} / 100$ hours & 5.75 & 1.95 \\
\hline
\end{tabular}

Figure 6.2.1 illustrates the reason for the differences in volume fraction. It can be seen that the difference is minimal between the TCP phase morphology and density for the $650^{\circ} \mathrm{C}$ and $700^{\circ} \mathrm{C}$ specimens as well as the 10 hour $750^{\circ} \mathrm{C}$ specimen. The specimen aged at $750^{\circ} \mathrm{C}$ for 100 hours shows significant precipitation of small TCP phase particles in both the primary and secondary interdendritic regions. Note: The lighter shaded interdentritic regions in Figures 6.2.1(a) through (e) are due to solute segregation and are not TCP phases. Only the brightest white regions are TCP phases.

The aging of specimens for this activity is still ongoing (see TWP-WIS-MD-000011) however, comparison of the results obtained for the 1.25 " thick welds with those previously obtained for 0.5 " welds aged at Haynes, International is shown graphically in Figure 6.2.2. The results for the aged 1.25" thick welds are superimposed on those obtained for the Haynes 0.5" welds aged at $649^{\circ} \mathrm{C}, 704^{\circ} \mathrm{C}$, and $760^{\circ} \mathrm{C}$ for similar times. It can be seen that for all specimens investigated in this work that the amount of TCP phases observed is comparable or less than that observed in the 0.5 " welds aged by Haynes, International. 
While many differences in welding parameters may exist between the 0.5 " and 1.25 " welds, it can be preliminarily concluded that at these times and temperatures, thick welds do not show a significant increase in TCP phase precipitation.
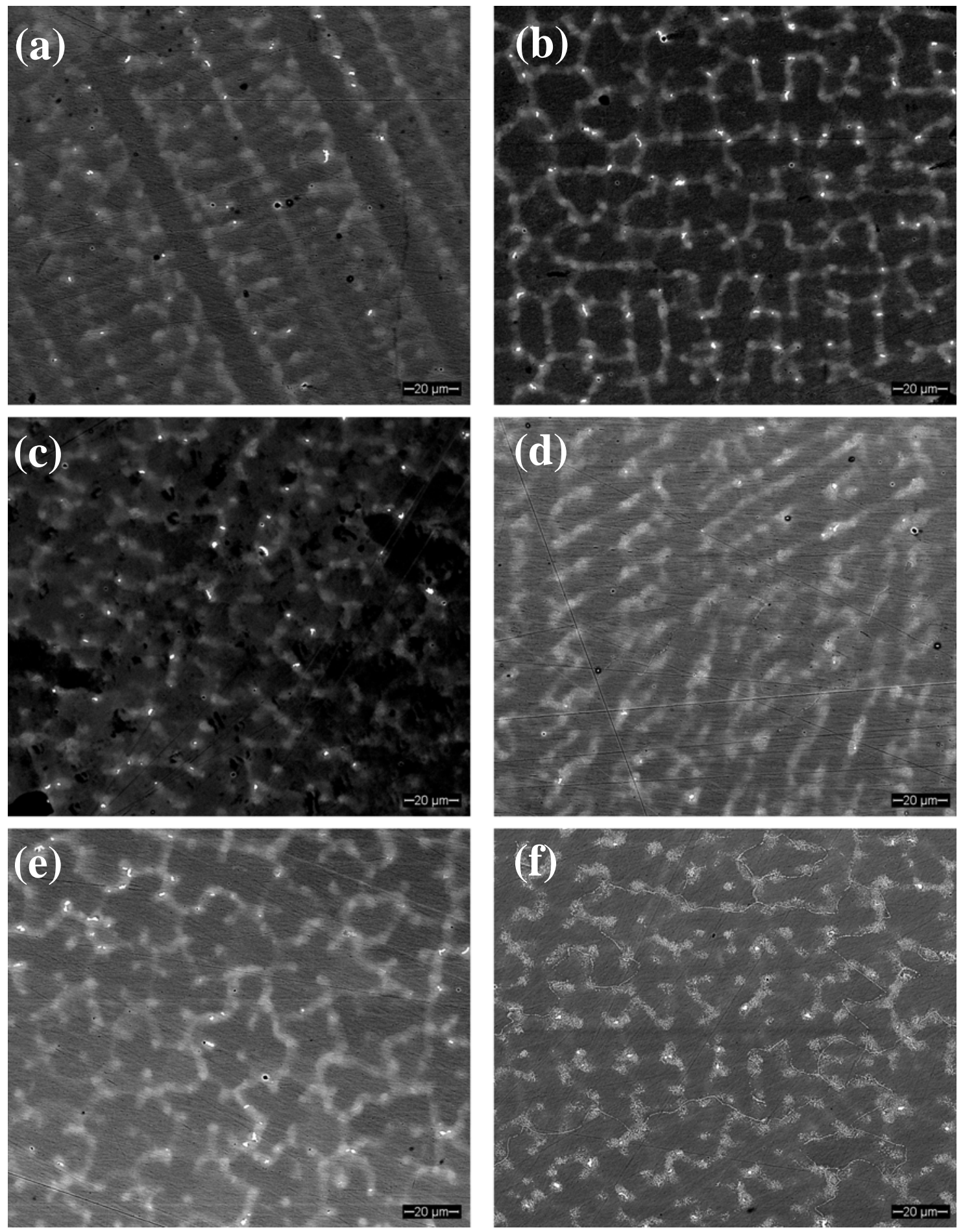

Figure 6.2.1. Backscattered Electron SEM Micrographs of specimens aged for (a) 20 hours at $650^{\circ} \mathrm{C}$, (b) 100 hours at $650^{\circ} \mathrm{C}$, (c) 10 hours at $700^{\circ} \mathrm{C}$, (d) 100 hours at $700^{\circ} \mathrm{C}$, (e) 10 hours at $750^{\circ} \mathrm{C}$, and (f) 100 hours at $750^{\circ} \mathrm{C}$. (Source: DTNs LL050304512251.138, LL050304612251.139, and LL050304712251.140) 


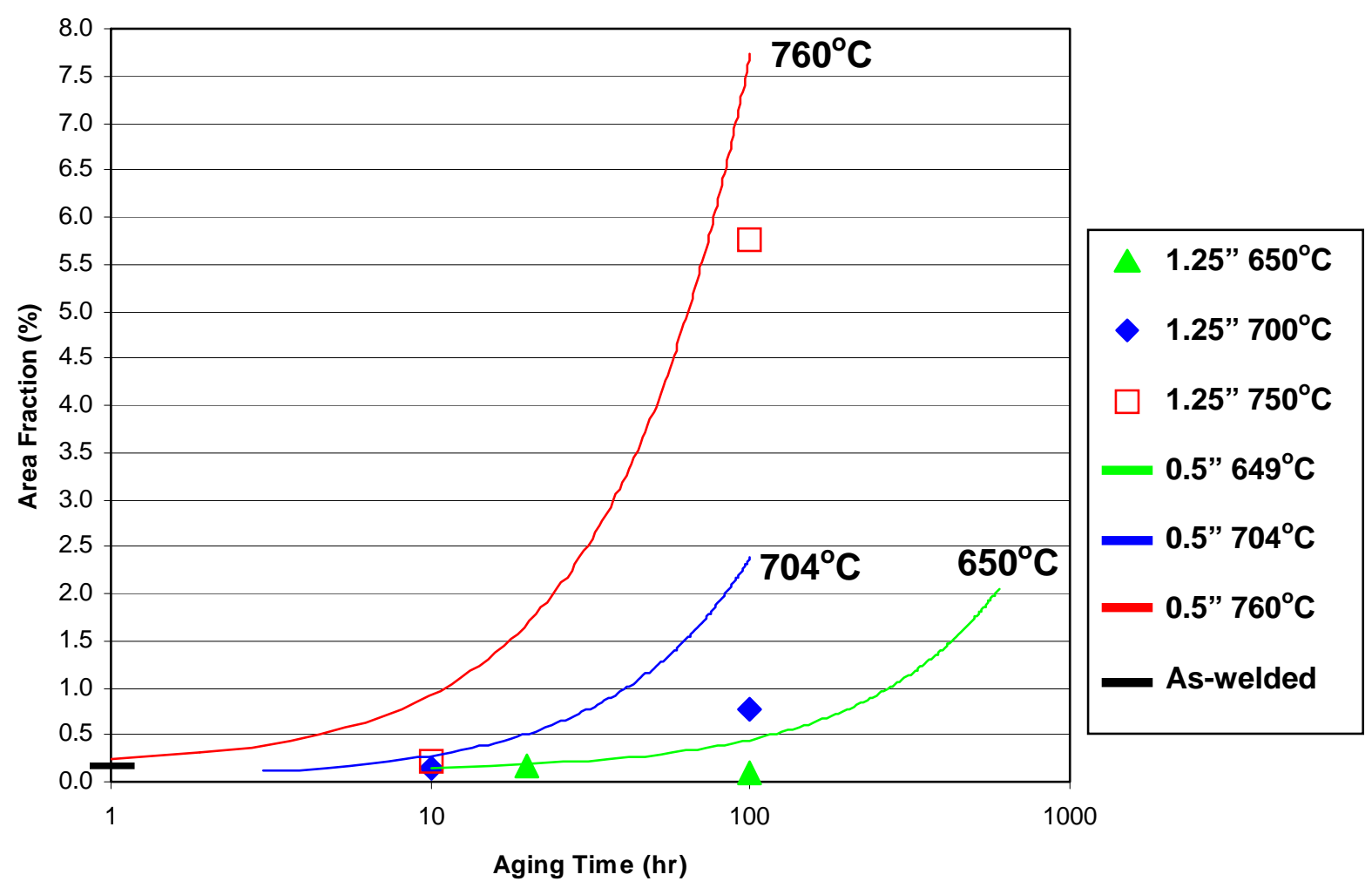

Figure 6.2.2. Plot comparing results for $1.25^{\prime \prime}$ welds aged at $650^{\circ} \mathrm{C}, 700^{\circ} \mathrm{C}$, and $750^{\circ} \mathrm{C}$ to previous work on 0.5 " welds. 1.25" weld data are represented by points, while previous data are shown as curves fit to the data. (Source: DTNs LL030103612251.006, LL050304912251.142 and LL030606912251.020)

\subsection{Summary}

Analyses of six of the seventeen Alloy 22 thick ( 1.25") weld specimens that were aged at 200 to $750^{\circ} \mathrm{C}$ (see TWP-WIS-MD-000011) were conducted. The specimens analyzed to date were those aged at $650^{\circ} \mathrm{C}$ for 20 and 100 hours and the remaining four at $700^{\circ} \mathrm{C}$ and $750^{\circ} \mathrm{C}$ for 10 and 100 hours. The TCP phase kinetics were fastest at $750^{\circ} \mathrm{C}$, resulting in an increase in volume fraction of TCP phases to approximately $6 \%$. While many differences in welding parameters may exist between the 0.5 " and 1.25 " welds, it can be preliminarily concluded that at these times and temperatures, thick welds do not show a significant increase in TCP phase precipitation. The TCP phase formation in an as-welded specimen and specimens aged for longer durations at these and other temperatures is on-going. 


\section{Haynes 11.4 year (100,000 hour) Aged Welds}

\subsection{Methods}

The characterization of welds aged by Haynes, International at 260,343 , and $427^{\circ} \mathrm{C}$ for approximately 100,000 hours was performed by Sandia National Laboratories (SNL). Although these specimens are still being studied (TEM analyses), it should be noted that the aged plates are only $0.5^{\prime \prime}$ thick and since there is not sufficient material to acquire corrosion/mechanical property data, the results presented are a limited metallurgical evaluation.

In previous TEM analyses of an Alloy 22 weld aged at $427^{\circ} \mathrm{C}$ for 40,000 hours performed at LLNL (see ANL-EBS-MD-000002), LRO was observed, and for this reason the welded specimen aged for 11.4 years at $427^{\circ} \mathrm{C}$ was prepared first for TEM study to determine the precipitation kinetics of the LRO phase. Since experimental verification of the extent, if any, of LRO transformations in the 260 and $343^{\circ} \mathrm{C}$ welded specimens is still ongoing at SNL, the results presented for specimens aged at these temperatures for 11.4 years will be limited to TCP phase transformations. TEM analyses performed at SNL of the welded specimen aged for 11.4 years at $427^{\circ} \mathrm{C}$ did qualitatively show the presence of LRO.

\subsection{Results and Discussion}

Figure 7.2.1 illustrates the locations (white box) where SEM micrographs were taken to document the presence of TCP phases for $0.5^{\prime \prime}$ welded specimens aged at 260 and $343^{\circ} \mathrm{C}$ for 11.4 years. The microstructure of both sides of the weld can be seen as well as the heat affected zone (HAZ) and adjacent base metal. Figure 7.2.2 (a) shows a micrograph of an as-welded, nonaged Alloy 22 specimen indicating the presence of TCP phases (bright white areas) resulting from the welding process. In the same figure, (b) and (c) show micrographs of the 0.5" welded specimens aged at 260 and $343^{\circ} \mathrm{C}$, respectively for 11.4 years also indicating the presence of TCP phases.

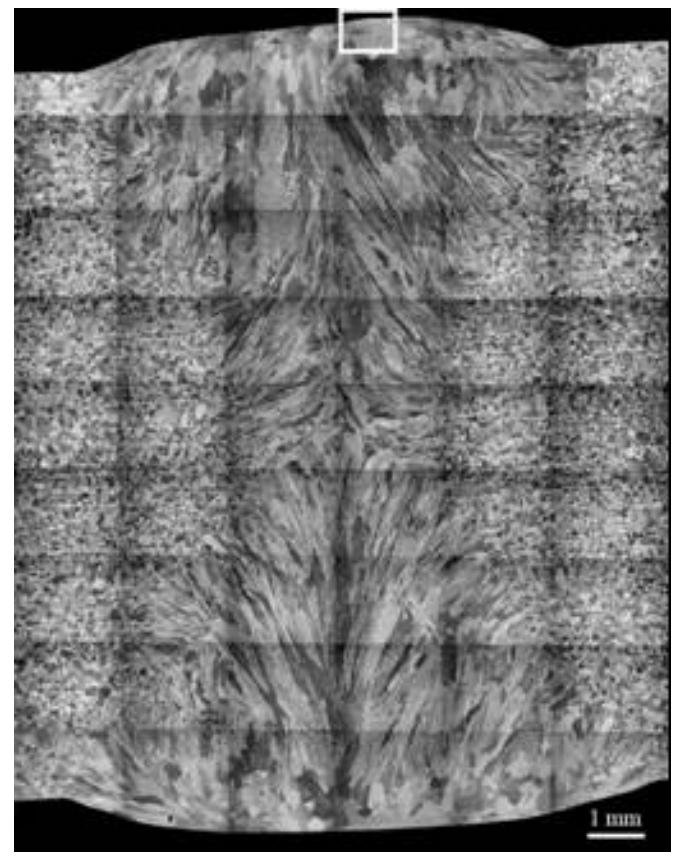

Figure 7.2.1. Overview micrograph collage illustrating the weld region (white box) examined for 0.5 " welded specimens aged at 260 and $343^{\circ} \mathrm{C}$ for 11.4 years. (Source: DTN LL050901512251.040) 
There is virtually no observable difference in the TCP phase size and morphology between the 11.4 year aged specimens ( $b$ and $c$ ) and the TCP phases created during the initial welding process in the as-welded specimen (a). $\mathrm{P}$ and sigma were the only TCP phases observed in the weld after aging at $427^{\circ} \mathrm{C}$ for 100,000 hours.
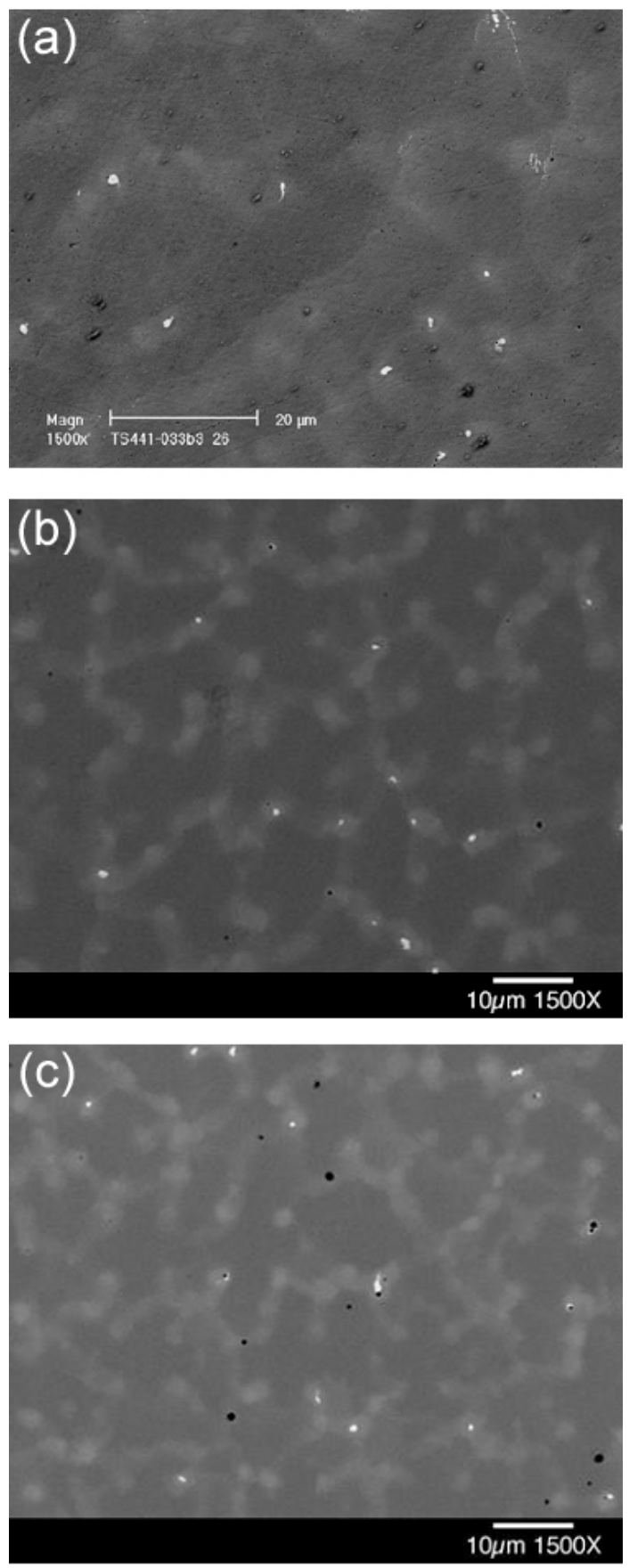

Figure 7.2.2. 1500X backscattered electron micrographs illustrating the TCP phase sizes and morphologies in 0.5 " welds for an (a) as-welded specimen, (b) specimen aged at $260^{\circ} \mathrm{C}$ for 100,000 hours, and (c) specimen aged at $343^{\circ} \mathrm{C}$ for 100,000 hours. (Source: DTN LL021009912251.003 and LL050901512251.040) 
The evolution of LRO at the aging temperature of $427^{\circ} \mathrm{C}$ as a function of time is illustrated in Figure 7.2.3. Previous TEM analyses by LLNL for an Alloy 22 welded specimen aged at $427^{\circ} \mathrm{C}$ for 40,000 hours had shown the formation of LRO with a very fine particle size that was uniformly distributed (a). In comparison, the welded specimen aged at $427^{\circ} \mathrm{C}$ for 100,000 hours shows a significant increase in the LRO phase size, as observed in Figure 7.2.3 (b). It is important to note that the precipitates in this welded aged specimen were not uniformly distributed, with some regions growing coarser precipitates (Figure 7.2.3 (b)) and other regions growing denser areas of smaller precipitates (Figure 7.2.3 (c)) . This is just one example of the difficulty involved in trying to develop a method to accurately determine values for the volume fraction of LRO in aged weld specimens. The LRO phase sizes analyzed by SNL were coarser than those observed by LLNL for an Alloy 22 welded specimen aged at $427^{\circ} \mathrm{C}$ for 40,000 .
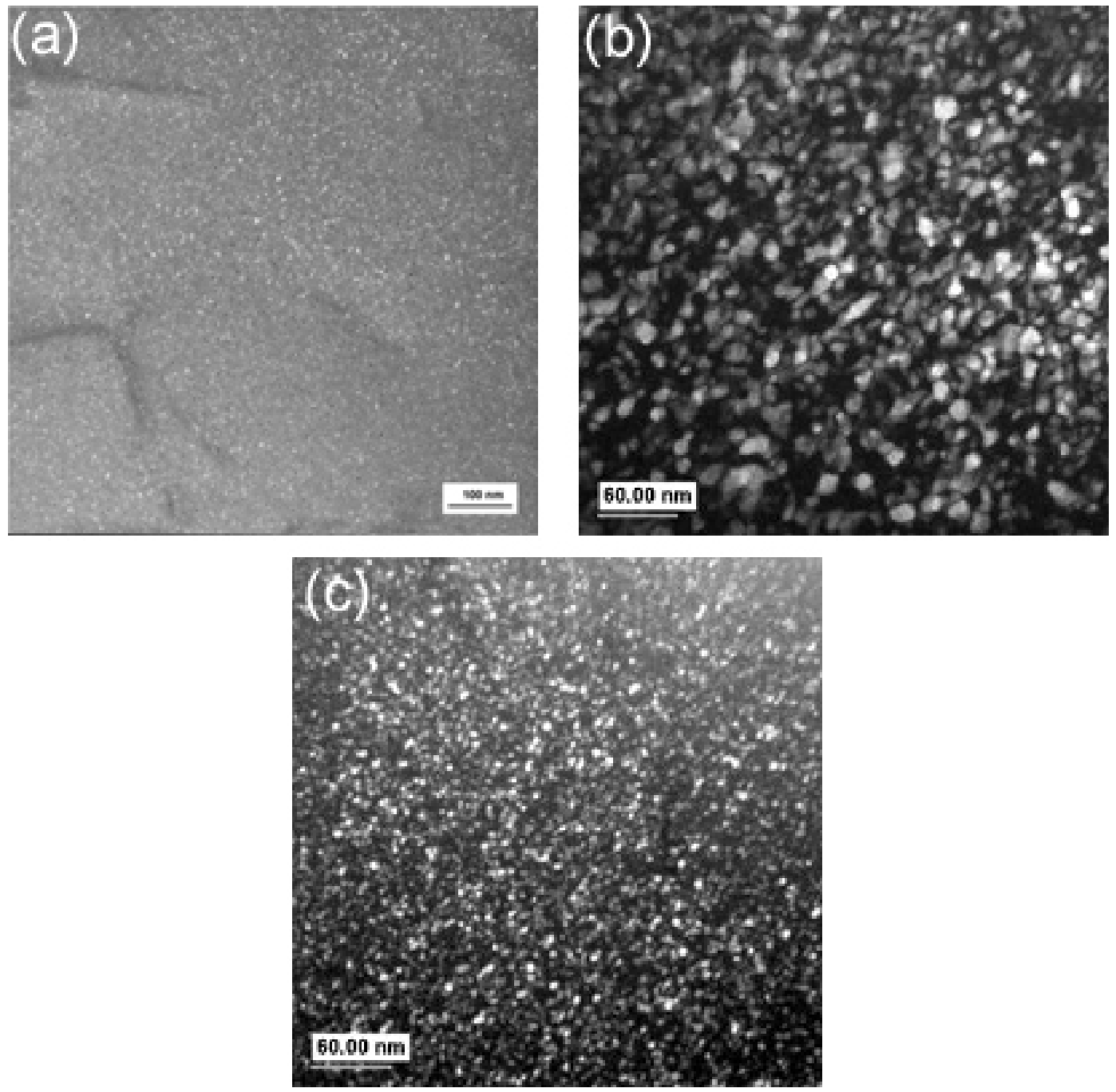

Figure 7.2.3. Transmission electron micrographs illustrating the differences in LRO phase sizes and morphologies in 0.5" Alloy 22 aged specimens for (a) welded specimen aged for 40,000 hours at $427^{\circ} \mathrm{C}$, (b) welded specimen aged for 100,000 hours at $427^{\circ} \mathrm{C}$, (c) another area for the same welded specimen aged for 100,000 hours at $427^{\circ} \mathrm{C}$. (Source: DTN LL030301612251.040 and LL050901412251.039) 


\subsection{Summary}

Comparison of a non-aged, as-welded specimen to specimens aged at $260^{\circ} \mathrm{C}$ and $343^{\circ} \mathrm{C}$ for 100,000 hours showed no differences in the TCP phase morphology and size. However, for the specimen aged at $427^{\circ} \mathrm{C}$ for 100,000 hours, the net amount of long range ordering appeared to increase, along with a substantial increase in the typical size of the LRO precipitate observed. $\mathrm{P}$ and sigma were the only TCP phases observed in the welds after aging at $427^{\circ} \mathrm{C}$ for 100,000 hours and LRO was also present. 


\section{References}

1. "Icosahedral Coordination in Metallic Crystals," Introduction to Quasicrystals, ed. M.V. Jaric (New York, New York: Academic, 1988), 1-57.

2. H.M. Tawancy, R.B. Herchenroeder, and A.I. Asphahani, "High-Performance Ni-Cr-Mo-W Alloys," Journal of Metals, 35 (1983), 37-43.

3. M. Raghavan, B.J. Berkowitz, and J.C. Scanlon, "Electron Microscopic Analysis of Heterogeneous Precipitates in Hastelloy C-276," Metallurgical Transactions A, 13A (1982), 979-984.

4. H.M. Tawancy, "Precipitation Characteristics of $\mu$-phase in Wrought Nickel-base Alloys and its Effect on the Properties," Journal of Material Science, 31 (1996); 3929-3936

5. "Phase Stability and Mechanical Properties of C-22 Alloy Aged in the Temperature Range 590 to $760^{\circ} \mathrm{C}$ for 16,000 Hours," in Scientific Basis for Nuclear Waste Management XXII, Materials Research Society Symposium Proceedings Volume 556, ed. D.J. Wronkiewicz and J.H. Lee, (Warrendale, PA: Materials Research Society, 1999), 919-926.

6. R.B. Rebak, T.S.E. Summers, and R.M. Carranza, "Mechanical Properties, Microstructure and Corrosion Performance of C-22 Alloy Aged at $260^{\circ} \mathrm{C}$ to $800^{\circ} \mathrm{C}$," (Paper presented at the 1999 Fall meeting of the Material Research Society, Boston, Massachusetts, 29 November 1999).

7. R.B. Rebak,, N.E. Koon, J.R. Dillman, P. Crook, and T.S.E. Summers, "Influence of Aging on Microstructure, Mechanical Properties, and Corrosion Resistance of a Ni-22Cr-13Mo-3W Alloy." (Paper presented at the NACE International Corrosion 2000 Conference, Orlando, FL, March 2000).

8. M.J. Cieslak, T.J. Headley, and A.D. Romig, Jr., "The Welding Metallurgy of Hastalloy Alloys C-4, C-22, and C-276," Metallurgical Transactions A, 17A (1986), 2035-2047.

9. J.S. Ogborn, D.L. Olson, and M.J. Cieslak, "Influence of Solidification on the Microstructure Evolution of Nickel Base Weld Metal," Material Science and Engineering A, 203 (1995), 134139.

10. R.B. Rebak and N.E. Koon, "Localized Corrosion Resistance of High Nickel Alloys as Candidate Materials for Nuclear Waste Repository. Effect of Alloy and Weldment Aging at $427^{\circ} \mathrm{C}$ for up to $40,000 \mathrm{H}$." (Paper presented at the NACE Corrosion 98 Conference, San Diego, CA, March 1998).

11. U.L. Heubner, E. Altpeter, M.B. Rockel, and E. Wallis, "Electrochemical Behavior and its Relation to Composition and Sensitization of NiCrMo Alloys in ASTM G-28 Solution," Corrosion, 45 (1989), 249-259.

12. S.J. Matthews, "Thermal Stability of Solid Solution Strengthened High Performance Alloys," in Superalloys: Metallurgy and Manufacture, Proceedings of the Third International Symposium, B.H. Kear, D.R. Muzyka, J.K. Tien, and S.T. Wlodek, eds. (Baton Rouge, Louisiana: Claitor's Publishing Div., 1976), 215-226. 